OPEN ACCESS

Edited by:

Alessandro Russo,

University of Pisa, Italy

Reviewed by:

Deron R. Herr,

National University of

Singapore, Singapore

Ana Afonso,

University of São Paulo, Brazil

*Correspondence:

Ralf A. Claus

ralf.claus@med.uni-jena.de

Specialty section:

This article was submitted to Infectious Diseases - Surveillance,

Prevention and Treatment,

a section of the journal

Frontiers in Medicine

Received: 12 October 2020 Accepted: 03 December 2020

Published: 20 January 2021

Citation:

Claus RA and Graeler MH (2021) Sphingolipidomics in Translational

Sepsis Research-Biomedical Considerations and Perspectives.

Front. Med. 7:616578.

doi: 10.3389/fmed.2020.616578

\section{Sphingolipidomics in Translational Sepsis Research-Biomedical Considerations and Perspectives}

\author{
Ralf A. Claus ${ }^{1 *}$ and Markus H. Graeler ${ }^{1,2,3}$ \\ ${ }^{1}$ Department for Anesthesiology and Intensive Care Medicine, Sepsis Research, Jena University Hospital, Jena, Germany, \\ ${ }^{2}$ Center for Sepsis Care \& Control, Jena University Hospital, Jena, Germany, ${ }^{3}$ Center for Molecular Biomedicine (CMB), Jena \\ University Hospital, Jena, Germany
}

Scientific Background: Sphingolipids are a highly diverse group of lipids with respect to physicochemical properties controlling either structure, distribution, or function, all of them regulating cellular response in health and disease. Mass spectrometry, on the other hand, is an analytical technique characterizing ionized molecules or fragments thereof by mass-to-charge ratios, which has been prosperingly developed for rapid and reliable qualitative and quantitative identification of lipid species. Parallel to best performance of in-depth chromatographical separation of lipid classes, preconditions of precise quantitation of unique molecular species by preprocessing of biological samples have to be fulfilled. As a consequence, "lipid profiles" across model systems and human individuals, esp. complex (clinical) samples, have become eminent over the last couple of years due to sensitivity, specificity, and discriminatory capability. Therefore, it is significance to consider the entire experimental strategy from sample collection and preparation, data acquisition, analysis, and interpretation.

Areas Covered: In this review, we outline considerations with clinical (i.e., human) samples with special emphasis on sample handling, specific physicochemical properties, target measurements, and resulting profiling of sphingolipids in biomedicine and translational research to maximize sensitivity and specificity as well as to provide robust and reproducible results. A brief commentary is also provided regarding new insights of "clinical sphingolipidomics" in translational sepsis research.

Expert Opinion: The role of mass spectrometry of sphingolipids and related species ("sphingolipidomics") to investigate cellular and compartment-specific response to stress, e.g., in generalized infection and sepsis, is on the rise and the ability to integrate multiple datasets from diverse classes of biomolecules by mass spectrometry measurements and metabolomics will be crucial to fostering our understanding of human health as well as response to disease and treatment.

Keywords: metabolomic analyses, sphingomyelin, ceramide, sphingosine-1-phosphate, mass spectrometryLC-MS/MS, theranostic 


\section{PROEM WHY SPHINGOLIPIDOMICS-WHY SHOULD WE DO ANALYSES FROM A CONVOLUTED BIOLOGICAL SYSTEM?}

Why one should do analyses from a complex and convoluted biological system, from which at least a proportion is understood in detail? Because (i) we are interested in a complete picture encompassing all or at least many members of this set of biomolecules, because (ii) these molecules are often interconvertible into each other by tightly regulated and dynamic mechanisms, because (iii) individual biomolecules exert synergistic, but also antagonistic properties in issues of life or death of a cell or of an organism, because (iv) we minimize on the basis of an unbiased and comprehensive profile the probability of misinterpretation, whenever we have a look to the bigger picture of a distinct phenotype, and finally, because (v) we are only that way able to discover relationships and mechanism of potential drugs in complex diseases. This justification should be captivating to task with thousands of molecules and complex bioanalytical procedures, since it is unknown which of the throng of metabolites in the samples will be of interest.

\section{SPHINGOLIPIDS-A MAJOR LIPID CLASS WITH BROAD STRUCTURAL AND PHYSICOCHEMICAL DIVERSITY}

\section{Backbone and Structure of Sphingolipids}

One of the few common features of sphingolipids (SP) is the hydrophobic sphingoid backbone as a building block, a long carbon chain with a nitrogenous head group (Figure 1). The most abundant sphingoid base is SPHINGOSINE with an 18-carbon chain, which is hydroxylated at positions 1

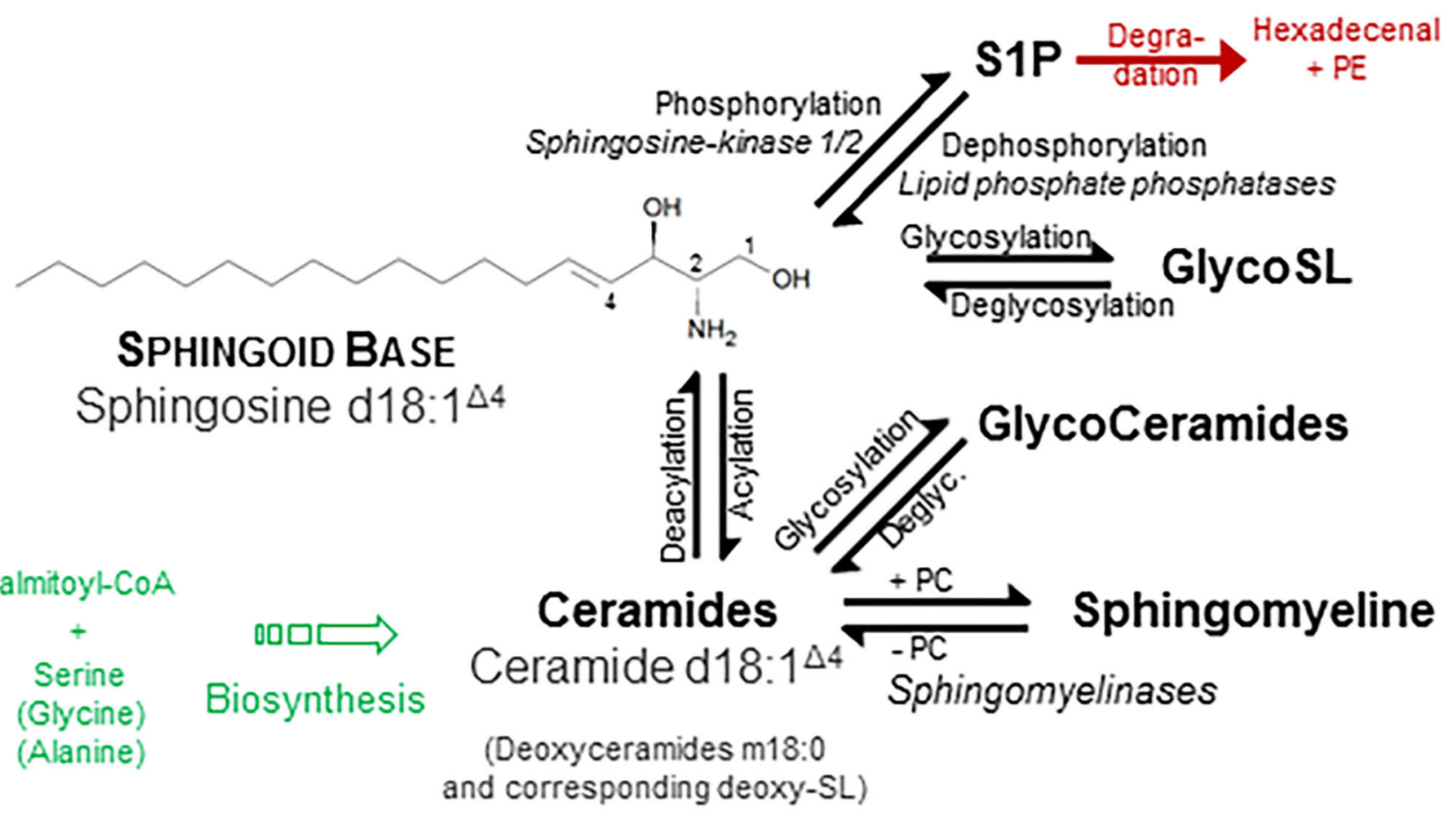

FIGURE 1 | Structural and physicochemical diversity of sphingolipids. Sphingolipids (SP) share a common hydrophobic SPHINGOID BASE structure, which most abundant species is SPHINGOSINE $\left(\mathrm{d} 18: 1^{\Delta 4}\right)(1)$. Diversity of SP originates from either discrete or common substitution at hydroxyl moiety (Pos. 1) as well as at the amino moiety (Pos. 2) and-more categorical-variation of the backbone with respect to number and position of hydroxyl groups and unsaturated bonds (not shown). Discrete phosphorylation of the hydroxyl group at position 1 results in the simple sphingoid base derivatives SPHINGOSINE-1-PHOSPHATE (S1P), acting at a family of G-protein-coupled S1P-receptors. Acylation of the amino moiety at position two establish the N-acylated sphingoid bases, termed CERAMIDES (Cer), where the fatty acid also varies in length (16-26 carbon atoms), hydroxylation, and saturation rate in a broad range. Esterification of these ceramides with phosphorylcholine (PC) results in the phosphono series of SP, esp. SPHINGOMYELINES. Additionally, glycosidic bonding of the hydroxyl group with mono- up to tetra-saccharides with different compositions initiates the most complex group of GLYCOSPHINGOLIPIDS, which are considered as derivatives of ceramide. For instance, a $\beta$-glycosidical linkage of D-glucose to the 1-hydroxyl moiety of ceramide results in formation of glucosylceramide (GlcCer). Ceramides, glycosphingolipids, and SM do not display a net charge and are therefore neutral sphingolipids, whereas linkage of glyco-sphingolipids with sialic acid or sulfate is negatively charged. Other sphingoid bases differ in number of unsaturated bonds (SPHINGANINE d18:0, syn. dihydrosphingosine; SPHINGADIENE d18:2 ${ }^{\Delta 4,14}$ ) as well as number and position of hydroxyl groups: PHYTOSPHINGOSINE t18:0 and DEOXYSPHINGOSINE m18:0. Use of alanine instead of serine as a building block in the first condensation step produces deoxysphingosine derivatives (m18:1). A plethora of additional variations are found in other organisms (2). Along chemical structures of individual lipids and their derivatives, categorization into distinct classes and subclasses, nomenclature, and cataloging of (sphingo-)lipids and of their properties were performed by the LIPID MAPS Consortium (3), most recently revised by leading authorities in the field (4). Similar to sphingosine, also Cer is phosphorylated to the bioactive lipid mediator Cer-1-phosphate (not shown) (5). Also, major SP classes are metabolically interconvertible by enzyme-mediated pathways (6, 7), some names of which are given in italic style. 
and 3 and unsaturated at one double bound (position 4). Written in shorthand for sphingolipidomics, thus sphingosine is $\mathrm{d} 18: 1^{\Delta 4}$, where the dihydroxylation status is termed by the "d." There are over a dozen variations in the backbone in terms of chain length, saturation (number of double bonds), branching (8), and finally the number and position of hydroxyl substituents (" $m$ " or " $t$ " denotes one or three hydroxyl groups, respectively) $(1,2)$. In mammals, the $\mathrm{d} 18: 1$ backbone is mostly predominant (9). Concerning the chain length of the acylated fatty acid, in heart tissue and also in plasma, predominantly a chain length of 16 carbons, in skin varying between 16 and 26, and in brain from 16 to 24 has been observed (911). One related group of simple sphingosine derivatives is the phosphorylated derivative SPHINGOSINE-1-PhOSPHATE (S1P). This lipid mediator has been identified as ligand for a family of G-protein-coupled receptors, termed by its agonist $\mathrm{S}_{1} \mathrm{P}_{1}$ to $\mathrm{S}_{1} \mathrm{P}_{5}$ $(12,13)$. Besides unspecific breakdown by some lipid phosphate phosphatases (14), the action of just one lyase-hydrolyzing S1P into phosphoethanolamine and hexadecenal in an irreversible manner-is the only known escape strategy from the universe of SP (15). A short overview is given in Figure 1.

\section{Biosynthesis}

Beyond structural and molecular diversity, the function of SP is also widely spread from constitutive, inert component of cellular membranes up to highly active compounds involved in cellcell recognition, growth, and signal transduction, to mention a few $(6,8,16-19)$. Sphingolipds and glycosphingolipids also undergo constitutive degradation in the endosomal/lysosomal compartment of a cell, which is in detail also a pathogenetic correlate for a series of inherited diseases, but beyond of the scope of this report $(20,21)$. Instead of serine as substrate for the first, rate-limiting step of SP DE NOVO biosynthesis, also the amino acid alanine or glycine can be used, resulting in the formation of deoxysphingolipids (22). Due to the lack of the essential hydroxyl moiety for phosphorylation, these aberrant species are unable to attain the conventional pool of SP or to be degraded by canonical pathways tending to accumulation with subsequent induction of mitochondrial dysfunction (23). Resolution of the extensive compositional and structural diversity of SP in biological systems is far from being completed, novel species are continuously discovered (24).

\section{SPHINGOLIPIDS-A MAJOR LIPID CLASS WITH BROAD (PATHO-) PHYSIOLOGICAL ACTIVITY PROFILE}

\section{Biosynthesis and Distribution}

For De novo SYNTHESIS of all SP, biosynthesis of ceramides (Cer) in the endoplasmic reticulum is the common starting point, which underlies extensive intra- and extracellular transport and secretion mechanisms and salvage pathways [excellently reviewed in (19) and references cited therein]. Beyond accumulation of SP in membranes of cells, platelets, and erythrocytes, more than 200 species are found in plasma (10) distributed to lipoproteins and albumin (Table 1). Interestingly, in a recently published study a universal and nearly linear decline of all major lipid classes in the second half of human lifespan in healthy individuals was reported, which was more pronounced in females. Interestingly, the lipidome in the super-aged subgroup (95 years+) was found to be mostly similar to that among younger subjects (30).

Despite that SP are present in all eukaryotic cells and body fluids, the relative abundance of individual SP species varies significantly among tissue, cell type, and activation status undergoing pathophysiological response or transformation. Then, SP often function as a consequence of physicochemical properties as well as pacemaker and biomarker in a series of conditions such as cancer (31-33), endotoxin triggered activation of macrophages $(34,35)$ or in liver tissue following inflammation (36) as well as severe infection by bacteria (37) or viruses (38), to mention a few. Principal functions of SP are given in Table 2. In overall terms, SP composition and content have the potential to provide "specific profiles" of cell types and underlying activation

TABLE 1 | Distribution of plasma-secreted sphingolipids.

\begin{tabular}{|c|c|c|c|c|c|c|c|}
\hline Class & Number & Rate & \multicolumn{3}{|c|}{ Distribution } & Comment & References \\
\hline Cer & 41 & $3 \%$ & \multicolumn{2}{|c|}{$48 \%$} & $52 \%$ & & $(10,25)$ \\
\hline GluCer & 56 & $9-10 \%$ & $8-14 \%$ & $46-60 \%$ & $28-44 \%$ & & $(10,25,26)$ \\
\hline
\end{tabular}

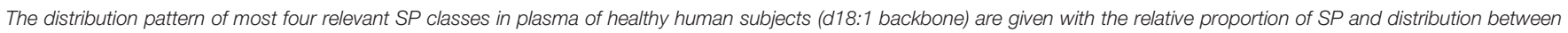

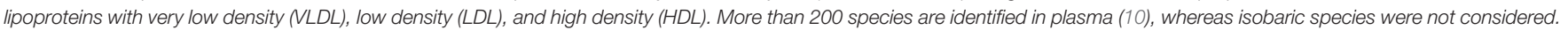

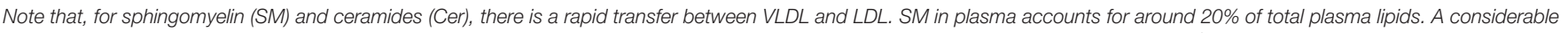

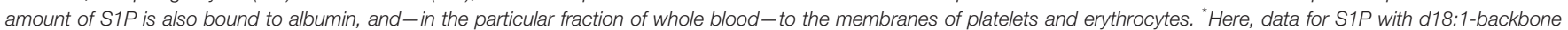

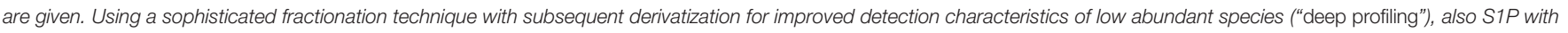
divergent backbones has been described (d16:1, d18:0, d18:2, and d20:1) (29). 
TABLE 2 | Coordinative function of sphingolipids.

\begin{tabular}{lll}
\hline $\begin{array}{l}\text { Coordinative } \\
\text { function of SP }\end{array}$ & Cellular response & References \\
\hline $\begin{array}{l}\text { Membrane } \\
\text { architecture }\end{array}$ & $\begin{array}{l}\text { Regulating membrane's } \\
\text { thickness, stiffness, and } \\
\text { curvature } \\
\text { Biogenesis of vesicles }\end{array}$ & $(39,40)$ \\
$\begin{array}{l}\text { Phase segregation } \\
\text { \& self-association }\end{array}$ & $\begin{array}{l}\text { Lateral sorting (formation of lipid } \\
\text { rafts) } \\
\text { Organization of both protein } \\
\text { distribution and its bioactivity }\end{array}$ \\
Cellular signaling & $\begin{array}{l}\text { Processing of extracellular } \\
\text { signals by GCPR } \\
\text { Cell-cell interaction (metabolism, } \\
\text { tumor invasion) }\end{array}$ \\
$\begin{array}{l}\text { Surface } \\
\text { recognition } \\
\text { molecules }\end{array}$ & $\begin{array}{l}\text { Host-pathogen interaction and } \\
\text { adhesion }\end{array}$ \\
\hline
\end{tabular}

An overview on the principal coordinative function of different SP regulating cellular response is given. Action of SP regulates the activation status of the cell, receiving, and processing of extracellular signals by G-protein-coupled receptors (GPCR) in issues of life or death, and interaction with either host cells or the prefacing contact during host response toward pathogens.

status as a specific criterion, of which a number of implications for translational value of SP analyses increased (6).

\section{Membrane Stabilization}

As a major component of the plasma membrane of all eukaryotic cells, SP represent up to a third of the membrane lipids, of which sphingomyelin (SM) is predominant and enriched in the outer leaflet of the membrane (46). Due to the fixed cylindrical formation and the intrinsic physical phase behavior, regulation of SP content in the membrane provides a biophysical mechanism to control the membrane's rigidity and shape (46). Softening the tight package is driven either by hydrolysis of SM to Cer and/or by the incorporation of cholesterol molecules (46-49). The interaction of linear acyl chains (either from SM and Cer) and flattened sterol rings (from cholesterol) results in lateral heterogeneity and spontaneous formation of so-called lipid rafts with unique scaffold properties and implications for protein assembly affecting signaling capacity $(50,51)$. The formation of these submicrometric lipid domains greatly contributes to membrane curvature, vesiculation properties and functionassociated shaping of cells, platelets and erythrocytes $(52,53)$.

\section{Signaling Performance}

Beyond this membrane-stabilizing action, a small proportion of SP is held responsible to directly affect signaling or to act as a signal mediator: especially, low molecular weight SP such as ceramides, sphingosine, and the phosphorylated derivatives Cer-1-phosphate as well as SPHINGOSINE-1-PHOSPHATE are best characterized to bear instant signaling performance (Figure 1) upon generation $(6,54)$. As a general role, the unphosphorylated form (Cer, Sph) is associated with rather antiproliferative and apoptosis-triggering effects, whereas the phosphorylated species (Cer-1-P and S1P) often show proliferative and antiinflammatory response $(6,55)$. In addition to the action of all of these four lipids as a second messenger, only S1P is binding and signaling with a specific family of five G-protein-coupled receptors $\mathrm{S}_{1} \mathrm{P}_{1}$ to $\mathrm{S}_{1} \mathrm{P}_{5}$ (13), which are expressed by nearly all mammalian cells. Action of S1P is pleiotropic and complex, for example the egress of lymphocytes from thymus and peripheral lymphoid tissue; the progression of coronary artery disease and tamoxifen resistance in breast cancer are given (56-58).

\section{SP as Markers and Mediators}

In addition to disorders with (monogenetic) defects in lysosomal degradation, a series of SP have been shown to be altered in a variety of diseases: dysregulated SP profiles were reported for metabolic diseases $(19,59)$ such as obesity $(60)$, non-alcoholic fatty liver disease $(61,62)$, and type 2 diabetes (63). Since SP function as important mediators in the central nervous system, it is not surprising that SP are also orchestrated as markers or mediators of autoimmune diseases such as multiple sclerosis $(64,65)$, in neuronal cell death (66), Alzheimer's disease $(66,67)$, stroke, post-stroke inflammation, and neuroprotective mechanisms $(68,69)$, as well as other age-related diseases $(70)$. For example, Cer accumulate within tissues and circulation during metabolic dysfunction, dyslipidemia, and inflammation. Elevated levels of just four ceramide species (16:0, 18:0, 24:1, 24:0) in plasma are predicting major adverse cardiovascular events including death in a diverse patient population referred for coronary angiography (71).

\section{SPHINGOLIPIDOMIC IN INFECTION AND SEPSIS}

In today's understanding, sepsis is recognized as a clinical syndrome that results from the dysregulated inflammatory response to infection ultimately leading to organ dysfunction and death (72). Thereby, sepsis should not be categorized to be either a sole pro- or anti-inflammatory syndrome but rather as a dynamic and variable continuum of overlapping immune mechanisms. Despite evolving progress in better understanding the complex role of SP in infection biology $(73,74)$, clinical sphingolipidomics of this highly conserved stress response pathway might offer a systematic reflection of pathogenetic pathways during host response in the presence of pathogens or pathogen-associated molecular patterns. Close supervision of systemic changes of the sphingolipidome could therefore help for a better understanding of pathobiology as well as development of drugs, for early diagnosis and for therapeutical monitoring of systemic infection $(75,76)$.

A bacterial toxin (Staphylococcus aureus $\alpha$-toxin) is able to activate the inflammasome and mediate the formation and release of cytokines by activation of the SM-degrading stress responsive enzyme acid sphingomyelinase with release of Cer, which was shown to be abrogated by pharmacological inhibition of the activated enzyme (77). 
As another factor of pathogenicity, pathogens (e.g., Legionella pneumophila) are found able to directly target the host's SP metabolism by degradation of S1P by microbial lyase activity, probably received by horizontal gene transfer, ultimately resulting in inhibition of autophagy during macrophage infection (78). Also, pathogens causing respiratory infections such as Chlamydia pneumoniae, Streptococcus pneumoniae, and Mycobacterium tuberculosis are known to exploit SP metabolism for their opportunistic survival by decreased S1P content in both circulation and lung tissue. The dysregulation of host's SP metabolism results in inadequate maturation of the phagolysosomal compartment, decreased activation of macrophages, and subsequently, ineffective control of mycobacterial replication/growth in macrophages (79).

In preclinical studies (minipigs and mice), inhalation of sphingosine was safe and effective to increase the tissue level in the luminal membrane of bronchi and trachea of an agent held responsible to be potent for elimination of pathogens such as Pseudomonas aeruginosa, Staphylococcus aureus, or Acinetobacter baumannii. This observation is opening a new promising opportunity for therapeutical management of complicated lung infections $(80,81)$. Inhibition of the S1P-degrading enzyme (S1Plyase) exerted tissue protective effects mediated by $\mathrm{S} 1 \mathrm{P}-\mathrm{S}_{\mathrm{P}} \mathrm{P}_{3}$ signaling as a potential therapeutic target increasing disease tolerance against murine sepsis (82).

There is a series of reports of deranged plasma composition of SP and/or of changes in the activity of circulating enzymes affecting SP in blood or at the outer leaflet of cellular membranes during infection (Table 3). In sepsis, endothelial dysfunction, especially barrier disruption, results in increased vascular permeability, edema, and insufficient tissue oxygenation; all of these pathogenetic phenomena are controlled (beyond others) by S1P. This SP is a signaling lipid that regulates important pathophysiological processes including vascular endothelial cell permeability, inflammation, and coagulation. In preclinical observational studies, reduced S1P levels in serum or plasma of sepsis patients were associated with the disease (83). Beyond other metabolites, serum concentrations of SP were altered in sepsis compared to systemic inflammatory response syndrome; thus, SM (d18:1/22:3) combined with a glycerophospholipid was recommended for sepsis diagnosis. Furthermore, changes of metabolites between sepsis and severe sepsis/septic shock also varied according to the underlying type of infection, showing that SM (d18:1/16:1) combined with other metabolites is associated with unfavorable outcome in community acquired pneumonia, intra-abdominal infections, and bloodstream infections, respectively (86).

In lung tissue pathobiology, alteration in SP metabolism is closely related to inflammatory reaction and Cer increase, which in particular favors the switch to pathological hyperinflammation (93).

In community-acquired pneumonia (CAP), the metabolite profile obtained from serum samples differentiated healthy controls from patients in a severity-specific manner, where a combination of lactate, sphingosine, and an androsterone derivative was superior to conventional clinical scoring (94).

TABLE 3 | Summary of studies identifying alterations in the sphingolipidome during infection.

\begin{tabular}{|c|c|c|c|}
\hline Disease entity & Alteration in Plasma & Comment & References \\
\hline \multirow[t]{4}{*}{ Polymicrobial sepsis } & $\Downarrow \mathrm{S} 1 \mathrm{P}$ & Inverse association with disease severity & $(83,84)$ \\
\hline & $\Downarrow \mathrm{S} 1 \mathrm{P}$ & Redistribution of S1P from albumin to $\mathrm{HDL}$ & (85) \\
\hline & $\Downarrow S M d 18: 1 / 22: 3$ & $\begin{array}{l}\text { In combination with a lyso glycerophospholipid for } \\
\text { early diagnosis }\end{array}$ & (86) \\
\hline & $\Downarrow S M d 18: 1 / 16: 1$ & $\begin{array}{l}\text { In association with other metabolites for prediction } \\
\text { of outcome }\end{array}$ & \\
\hline & $\begin{array}{l}\Uparrow S M d 18: 0 / 16: 0 \\
\text { SM d18:1/16:0 } \\
\text { LacCer d18:1/16:0 }\end{array}$ & $\begin{array}{l}\text { Distinguishing CAP from the non-infection and from } \\
\text { extrapulmonary infection as well as non-CAP } \\
\text { respiratory tract infection subgroups }\end{array}$ & (88) \\
\hline & $\Uparrow$ Sphingatrien d18:3 & $\mathrm{SP}$ of bacterial origin as a diagnostic biomarker & (88) \\
\hline & SM d18:1/22:1 \& 22.2 & Association with outcome, also in COPD patients & (89) \\
\hline \multirow[t]{3}{*}{ COVID } & $\Downarrow \mathrm{S} 1 \mathrm{P}$ & Raise in subset of patients at hospital discharge & (90) \\
\hline & $\Uparrow S M d 18: 1 / 18: 1$ & Increase (top 10 marker) & \\
\hline & $\Downarrow$ Glucosylated Cer & Decrease (top 10 marker) & \\
\hline \multirow[t]{2}{*}{ Dengue fever } & $\Downarrow S M d 18: 1 / 16: 0$ & $\begin{array}{l}\text { Major changes in early febrile stages, normalization } \\
\text { to control levels at convalescent stage }\end{array}$ & (91) \\
\hline & $\Uparrow$ ceramides & & \\
\hline $\begin{array}{l}\text { Endotoxin neutralizing } \\
\text { therapy in septic shock }\end{array}$ & $\Uparrow S 1 P$ & $\begin{array}{l}\text { S1P increase function as predictor of therapeutical } \\
\text { effectiveness }\end{array}$ & (92) \\
\hline
\end{tabular}

Change of plasma concentration is given either by an up or by a down arrow. 
Furthermore, plasma levels of S1P were markedly elevated in CAP patients and were inversely correlated with disease severity and with predictive power for duration of hospital stay, ICU admission, and unfavorable outcome (87). In another study, (dihydro-) SM (d18:0 rsp. 18:1/16:0) and three glycosylated ceramide derivatives distinguished (among lysophosphoethanolamines) also in serum samples of CAP patients from healthy controls and allowed discrimination of CAP cases from the non-infection, extrapulmonary infection, and nonCAP respiratory tract infection subgroups (88). Levels of SM species were significantly lower in CAP patients $v s$. those with exacerbation of chronic obstructive pulmonary disease (COPD), and SM (d18:1/22:1 \& 22:2) were found to be associated with lower risk for short-term adverse outcomes, but not with long-term mortality rates (89). Similar results with decrease of SM in association with increase of Cer were also found, comparing CAP vs. patients with COPD and healthy controls. Interestingly, a disease relevant increase of the enzymatic activity of the corresponding enzyme, acid sphingomyelinase (SMPD1), was also verified, in both plasma (protein-level) and mRNA levels obtained from circulating leukocytes (95).

Among the top 10 metabolites distinguishing healthy control subjects from patients undergoing COVID-19, S1P was found to be reduced; however, its level was raised at hospital discharge relative to admission in a small subset of patients followed longitudinally (90). In these patients, increases in lysophospholipids (lysophosphatidic acids and lysophosphatidylcholines) as well as SM (d18:1/18:1, also top ten rated in this study) and glucosylated ceramides were contrasted by a decrease of neutral lipids. Most recently, serum S1P levels (determined using an immunological technique) were found to be inversely associated with COVID-19 severity: a significant correlation with markers for tissue damage, inflammation, and coagulopathy was determined (C-reactive protein, lactate dehydrogenase, ferritin, and Ddimers). Interestingly, the S1P decline was strongly associated with the number of red blood cells, the major source of plasma S1P, and both apolipoprotein $M$ and albumin, the major transport proteins of S1P. Furthermore, S1P was exhibiting strong predictive value for admission to ICU and patient outcome, for morbidity and severity of the clinical course. As a consequence, restoration to normal S1P-values was supposed as a therapeutic strategy in patients with COVID-19 (96).

Major changes in early febrile stages in Dengue fever were observed with respect to the SM/Cer ratio with a normalization to control levels at the convalescent stage (91). Unfortunately, in this study the activity of the converting enzyme (acid sphingomyelinase/SMPD1) was not monitored, but an association of membrane SM content to replication of flaviviruses could be confirmed (97).

Most interestingly, S1P monitoring (i.e., increase) was tested to function in a reliable manner to predict therapeutical effectiveness of an endotoxin absorption strategy using polymyxin B-immobilized hemoperfusion in patients with septic shock (92).

\section{Broad Horizon and Mean Limitations With Appropriate Quality Control in SP-Analysis}

For profiling the patterns of glycero-, phospho-, and SP-based on mass spectrometry (MS), the two most common approaches include analyses either by direct infusion (SHOTGUN-MS) or following chromatographic separation.

\section{Analytical Affairs}

The two main proceedings for analysis of (sphingo-)lipids are differing in the analysis of individual molecular species (specificity), resolution, and sensitivity. In an approach termed "SHOTGUN" from a crude complex extract, SP species are analyzed without any purification and/or chromatographical separation (98-101). For identification of highly abundant lipids, this method is quite simple and effective but fails completely with respect to resolution of isobaric compounds. Also, suppression of signal intensity by matrix constituents (see below) from the lipid extract is an intrinsic and fundamental limitation. Despite attempts to overcome this restriction either by mild hydrolysis of neutral glycerophospholipids or by selective derivatization for improved detection of low abundance SP (98, 102), this technique is far beyond reliable and wide-ranging analysis of clinical samples.

In a second, more common approach an upstream chromatographic separation is performed; thus, matrix suppression by co-eluting compounds is often overcome. On the other hand, used gradient protocols for chromatographic separation are time consuming, eluents might also affect ionization efficacy (103), and finally both amount and number of species detected in parallel are limited $(104,105)$. Noteworthily, the acute phase protein CRP, already abundant in circulation of septic patients, is known to effectively bind phospho- and sphingolipids, raising the question, whether an observed decrease of these lipids might just be fabricated and might be caused by an ineffective extraction procedure under these circumstances. However, this competent concern could be overcome by spiking experiments with recombinant protein prior to precipitation (95).

There, a series of methods has been developed for characterization and quantitation of SP; the detailed description and discussion is beyond the scope of this review [(103), for excellent review see $(105,106)$ and references cited therein]. For selection of the most appropriate method, there are some critical criteria discussed in more detail.

Reliable analyses of SP from clinical samples require specialized instrumentation (i.e., triple quadrupole mass spectrometer directly coupled to a high flow capacity ion source-ESI or APCI) and qualified users. There are some excellent publications to familiarize beginners in the field with the approach of sphingolipidomics (107). These general methods should be refined for the specific sample series to be tested since the head group, sphingoid bases, and fatty acid substituents are differing in a broad range as discussed previously, also affecting analytical performance. In ESI-positive mode, unique molecular decomposition products using precursor ion scans are the method of choice (Table 4). The complete fragmentation 
TABLE 4 | Common fragmentation ions of SP (ESI+ ${ }^{+}$-mode).

\begin{tabular}{lc}
\hline Sphingolipid species & Fragment ion [m/z] \\
\hline Sphingosine & 264,266 \\
Sphinganine & \\
Sphingosine-1-phosphate & \\
Cer & 264,266 \\
GlcCer & 264,266 \\
SM & 184
\end{tabular}

Optimal conditions for ionization as well as for collision for each SP species should be determined by representative compounds and/ or internal standard compounds, thus preventing molecular decomposition prior to reaching Q1 and also compensating intrinsic differences in the dissociation rate. Fragment ions of $\mathrm{m} / \mathrm{z} 264$ and $\mathrm{m} / \mathrm{z} 266$ are indicating a sphingoid base building block (SPB, d18:1, d18:0, respectively), which is representative for most naturally occurring sphingoid base chains. Differentiation of those SP will be achieved by either specification of retention time during liquid chromatography and/or by monitoring the specific fragment ions corresponding to molecular species (108).

TABLE 5 | Fragmentation profile of the trihexoside globotriaosylceramide Gb3 (d18:1/23:0).

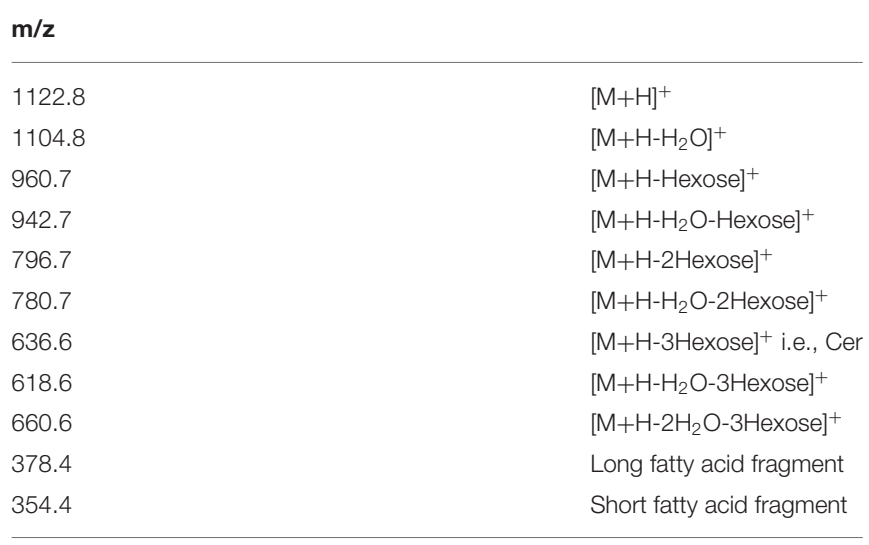

There is a sequential loss of hexoses with an apparent molecular weight of 162 each including corresponding dehydrated derivatives. The fragment with a molecular weight of $\mathrm{m} / \mathrm{z}$ 636. 6 corresponds to the unglucosylated ceramide molecule $>$ Cer d18:1/23:0 < with an exact mass of $635.622 \mathrm{u}(109)$.

pattern should be perceived for reliable identification of a SP class. This approach will allow the differentiation of compounds in case of isobaric precursors, e.g., SP with either Cer18:1/22:0 and its isobaric dihydroderivative Cer (d18:0/22.1) as a building block ( $\mathrm{m} / \mathrm{z} 621.606$ each, but difference +2.0 in sphingoid base fragmentation pattern, 264.3 and 266.3, respectively) (Table 5). For unique confirmation of candidate spectra, it might also be of great advantage, since there is a known ratio between different transition intensities from internal standard compounds, which is termed the qualifier ion ratio (110).

Determining lipid profiles in large cohorts of clinical samples and translational studies motivates to complex logistic measures to minimize technical variations within and also between laboratories (111).

\section{Sample Integrity}

Due to dissimilar physicochemical properties of used anticoagulants, extraction efficiency might be affected with respect to several compounds or to the global recovery rate $(25,112)$. Up to now, there is no general recommendation for use of a distinct anticoagulant for sphingolipidomic studies, but the same should be used throughout the study for prevention of unforeseen discrepancies (see below).

\section{Preanalytical Purification Procedure (PPP)}

There are a number of mono- and biphasic extraction procedures from plasma or serum described, which are all used for deprivation of proteins in the sample. Most methods-with decades of experience-are either based on a modified FOLCH extraction (113) or BLIGH \& DYER procedure (114). Some recent developments resulted in the validation of extraction methods combining advantages of efficiency, high throughput, and automation. There are two major issues taken into account for best preanalytical performance: from a technical point of view, harvesting of the organic layer from biphasic systems is one of the most critical issues during workflow, since a chloroform-borne organic phase due to higher density remains at the bottom of FOLCH and BLIGHT \& DYER procedures. Thus, collecting this lower phase is allowing range for variability due to contamination (non-lipids, proteins, salts) or leakage (nonquantitative extraction). Since our sphingolipidome encompasses a broad polarity range of compounds-as outlined in Figure 1 from uncharged to amphiphilic species (115)-efficiency of the extraction methods is highly pressed to work without discrimination of a class of compounds with overall coverage of almost all compounds from the sample, technical efficiency, and total throughput.

Beside sophisticated methods, also methanol-driven precipitation of proteins might have shown the best performance, as it does not lose many analytes, consisting of only a single precipitation step. Biphasic extraction procedures, in contrast, separate the analytes into two phases, and although the polar and non-polar compounds are meant to be enriched in either the aqueous or the organic phase, the amount of each analyte might still be split into both phases to some extent. Therefore, a single aqueous or organic phase might never contain as much analyte as the methanol precipitation extract where no separation step occurred. It is also known from other comparative studies that compared to biphasic extraction procedures (FOLCH, BLIGH, AND DYER) the methanol precipitation protocol $(80 \%, \mathrm{~V} / \mathrm{V})$ yielded regularly to higher for both exogenous and endogenous compounds (116).

There are also recently developed methods for one-step extraction of both Cer and SM from human plasma by a butanol:methanol mixture (BUME) (117). Monophasic procedures are regularly characterized by higher reproducibility and recovery rate, allowing automated high-throughput procedures (118). As a specialized method for use with low-level human samples, derivatization of long-chain base phosphate derivatives with extraordinary backbone (i.e., S1P derivatives; $\mathrm{d} 18: 2$, t20:1, or odd carbon forms) might improve the detection rate (29). Whatever you do, careful consideration and best performance of the lipid extraction method control overall quality of the analysis. 


\section{Workflow at the Machine}

Some easy, feasible, and pragmatic procedures for in-line monitoring of the analytical process for metabolomic profiling control the overall output of the study. Beyond design of the clinical study and following PPP, the design of the experimental workflow is the next quality-determining step. Due to the fact of long-lasting longitudinal studies, the samples run over a period of time and/or in an intermittent manner. For prevention of bias, proper randomization is critical for minimizing bias and variance. For these aims, "block randomization" is a commonly recommended method, which run sequentially in separated, rather homogeneous subcohorts $(119,120)$. Another techniqueborne confounding factor is given by the tendency of the mass spectrometers for a moderate drift over a long-lasting run, compromising quality of continuously running data over time in high-throughput screenings (119). There are some easy protective mechanisms against instrument-driven bias: the standard approach is preparation and use of specific quality control samples, which are collected with aliquots from every sample to generate a representative pool prior to sub-aliquoting into a set of study-specific, uniform quality control (QC) samples
$(121,122)$. The QC specimens are running together with the experimental samples and are integrated into the workflow at the beginning, in a regular and periodic basis throughout the run and finally at the end $(121,122)$. As a consequence, data quality of the complete analysis can be easily evaluated by a synoptical comparison of QC samples. As a key quality factor, variance of the signals of all the QC samples should be evaluated $(121,122)$. With two distinct sets of QC samples, the study director is able for efficient monitoring of both drifts caused by instrumental changes and "wet-lab" non-conformance during sample preparation (see in detail Figure 2). Since in large, long-lasting clinical studies preparation of the QC-samples will hamper to start an interim analysis with the first batches of samples, batch-specific QC-samples from individual subcohorts should be prepared, which might differ with respect to the absolute values of compounds, but should be similar with respect to overall variance (119). Antecedent definition and documentation of maximum tolerable values of variance in the study protocol outline a supreme performance of the analyses (121). There are also initiatives to improve reproducibility, accuracy, and precision of lipid quantitation, study design,

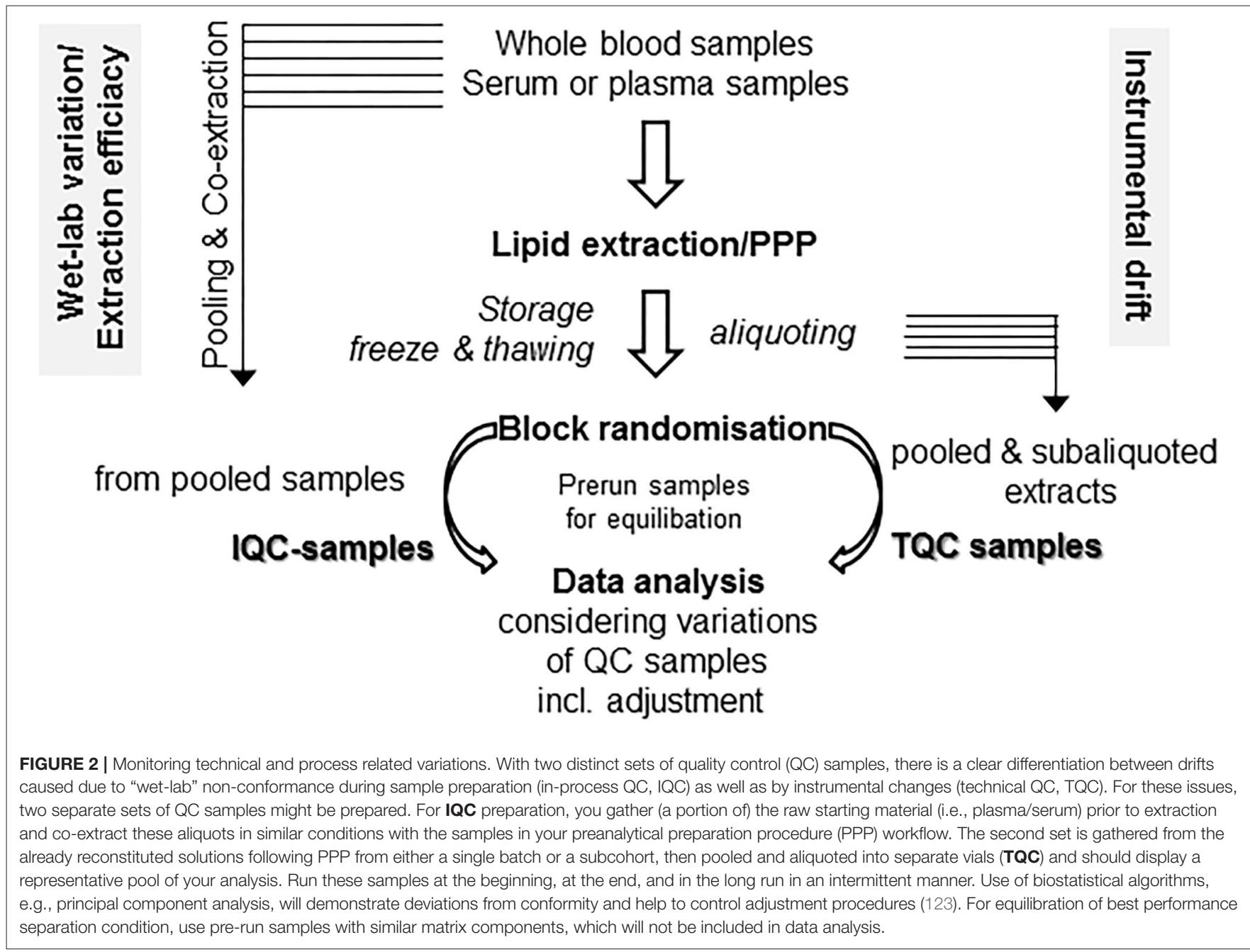


sample handling, and data/sample sharing for quantitative MSbased lipidomics of blood plasma or serum, with harmonization of data acquired on different instrumentation platforms across independent laboratories as an ultimate goal (124-127).

There are also some technical issues of LC/MS instrumentation resulting in increased variance parameters to take into account: conditioning of the separation media at the LC column seems to function as a critical factor with respect to generation of high-quality data $(128,129)$. Thus, in addition of equilibration of the column material in several blank runs, stabilization of the tightly balanced binding equilibrium is of great importance. For these aims, a precarriage of the column by use of samples with similar composition (especially in term of matrix composition), which are however insignificant for later data interpretation, will help to adjust retention times, mass accuracy, and signal intensity at a maximum level and excellent repeatability (119).

At the end, a sufficient number of QC samples will also help to overcome batch effects, i.e., the drift of signal intensity and retention time across different batches (130). Now, data sets might be adjusted by proper batch correction principles, when there are adequate guardians of study execution with respect to number and quality of these samples $(130,131)$, which ultimately also control the accuracy of the post hoc adjustment $(123,131)$.

\section{Sample Preparation}

There are different extraction methods for best performance of global profiling of SP without discrimination of low abundant species. To prevent chromatographic interference with glycero/phospholipids (1) or to reduce a potential matrix effect (132), in some procedures an alkaline hydrolysis is reported. Despite the elimination of a plethora of co-eluting compounds by saponification of ester bounds, the slow hydrolysis of the amide bound in SP should also be taken into account as a potential biasing factor and tightly controlled by spiking of internal standard compounds.

Methods for sample preparation differ fundamentally in MODUS OPERANDI: either precipitation of proteins with more or less complete release of SP from those binding partners or methods driven by distribution of SP between phases with variable lipophilicity. It is noteworthy that the latter approach deals with a non-quantitative enrichment process, which can also result in depletion or dislocation of the original profile but also removal of matrix-driven extinction of weak signals. Finally, there are also procedures utilizing the broad affinity of SP to solid matrix materials for removal of other (plasma) constituents. Parchem and colleagues recently published an excellent synopsis on sample preparation techniques for all phospholipid classes (133).

\section{Stationary and Mobile Phases}

Silica gel particles as stationary phase combined with a linear gradient of the mobile phase with increasing polarity is able to separate cholesterol, ceramides, and derivatives thereof (GlcCer, LacCer, Gb3, and Gb4) as well as SM in an order of elution along the increasing polarity of the head groups. In this homologous sequence of SP, convincing baseline separation is a conditio sine qua non, which can be also achieved by smart design of the gradient for clear separation of epimeric glycosylated ceramide derivatives such as GlcCer and GalCer (132). Using a reversedphase system (C-18 column, $150 \mathrm{~mm} \times 2 \mathrm{~mm}, \sim 2.7 \mu \mathrm{m})$, a segmented linear gradient has been demonstrated as an effective option for optimal and fast separation of SP (103).

\section{Source}

Coupling the outflow of an liquid chromatography apparatus online to a mass spectrometer with an atmospheric pressure chemical ionization interface (APCI) is typically used for analyzing less polar molecules from biological samples (134). Ionization by APCI is rather insensitive to signal impairing effects by the carrying solvent with an overall low tendency for adduct's formation. Due to the fact that APCI is a rather harsh ionization procedure, you often observe in-source fragmentation, where the building blocks of the SP occasionally can be verified in the full-scan spectrum of the molecule: from a synthetic and purified globotriaosylceramide with three hexosid molecules (Gb3, d18:1/23:0), all three characteristic components might be identified (109). Besides the molecular ion $[\mathrm{M}+\mathrm{H}]^{+}$and the dehydrated ion $\left[\mathrm{M}+\mathrm{H}-\mathrm{H}_{2} \mathrm{O}\right]^{+}$, the carbohydrate moiety, the Cer-backbone, and the fatty acid residue are found, whereas there is also a stepwise loss of carbohydrate residues, each of them also with a corresponding dehydrated species (Table 5).

An electrospray ionization interface (ESI) is complementary to APCI, which revolutionized the ability to generate intact molecular ions from polar biomolecules, which was therefore broadly used for structural characterization as well as quantitative and qualitative analysis of SP (135-137). This technique is sensitive to adduct formation, e.g., in the presence of ammonium ions, which might increase the sensitivity of the method. In the positive mode, you regularly detect the molecular ion $[\mathrm{M}+\mathrm{H}]^{+}$ as well as a common class-specific fragment, which sometimes hampers the precise mapping of isobaric compounds of a homologous sequence.

\section{Amount/Detection Limit}

(i) In some cases (esp. following alkaline hydrolyses), it is strictly recommended to dispose the fractions with free fatty acids (either at the start or at the end of the run, depending on polarity of the stationary phase) to prevent contamination of the source as well as an overload of the detector with free fatty acids from glyerophospholipids, cholesterol esters, and glycerolipids. (ii) Due to the broad range of abundance of naturally occurring SP, the injection volume of the sample (i.e., the total amount of SP species on the column) must be thoroughly evaluated, since a higher amount might increase signal intensity at all, but impairs separation efficiency of the column and signal intensity of lowabundance species due to unforeseen matrix effects of co-eluting compounds. Specification of the ideal injection volume should be performed following stepwise increase and comparison of signal characteristics of low-abundance species. (iii) The lower limit of detection (LLD) normally lies around 0.05-0.1 nmol, whereas the non-substituted SP (i.e., Cer, sphingosine) have the lowest. In glycol-SP, the LLD increases with the degree of substitution. (iv) Beyond the absolute amount of a species in 
the mixture for analysis, the stability of the fragment is also a critical factor to be taken into account. For example, the LLD of the cholesterol molecule is surprisingly high despite the weak stability of the detected molecular ion $\left[\mathrm{M}+\mathrm{H}-\mathrm{H}_{2} \mathrm{O}\right]^{+}$, which is but yet counterbalanced by high concentration in mostly all biological samples.

\section{Sensitivity and Specificity}

Reliable identification and quantitation can be achieved on the basis of the improved performance (esp. high-speed scans) of newer instrumentation in the last decades. Thus, identification is performed in tandem mass spectrometers (MS/MS) with precursor ion scans, to distinguish various SP species from crude biological mixtures by their unique decomposition products $(107,138)$. One significant advantage of this approach is the fact that both combination and molecular composition of building blocks can be readily determined (138). Automated suppression of the background noise of the instrument realizes much lower limits of detection. Quantitative performance is optimized by use of a specialized technique termed multiple reaction monitoring (MRM); since the time period for detection of precursor/product ion transitions is increased to a maximum, the time period for scanning regions without any interest reduced to a minimum. All in all, this approach yields in high sensitivity (with respect to LLD) and high specificity compared to precursor ion scan alone. If available, detection performance of individual lead compounds (representing a class of analytes) might also be optimized with respect to ion formation and fragmentation pattern including instrumental setting for best performance with respect to formation and detection. However, one limitation for absolute quantitation of SP is the fact that just for a minority of compound classes certified internal standard derivatives are available.

\section{Starting Material and Its Processing Procedures}

As most commonly used for the purpose of longitudinal clinical studies, we here focus on whole blood-drawn by venipunctureand "products" thereof as starting material for sphingolipidomic analyses. There is a long list of anthropometric factors, all having an impact of SP profiles also in healthy individuals (age, gender, ethnicity, etc.) $(30,139,140)$. Also clinical factors are affecting the SP profile (diet/fasting status, medication, diurnal variation, etc.), which should all be documented (141). With respect to storage, sample handling, use of quality controls, and sharing of reference material for harmonization of results between laboratories, we refer to previously published papers $(121,122,127,142)$. In general, up to two freeze/thaw cycles did not substantially affect metabolic profiles (140, 143-145), but with increasing numbers significant changes were observed, e.g., with respect to an increase of arachidonic acid content, probably a reflection of ongoing metabolism, to which also SP are sensitive (144).

\section{Plasma or Serum?}

Next, it is noteworthy, that the (anti)coagulation strategy per se massively affects the SP profile (25). Moreover, the liquid fractions of whole-blood preparations (plasma vs. serum) should be considered as completely different materials, which are now and to no time comparable with respect to SP profile (27, $146,147)$, which might be caused at least by clotting-associated alterations and release of metabolites and enzymes further metabolizing them (148). As an example, export mechanisms of (activated) platelets are held responsible to control S1P concentration in plasma measurements (149). In a series of studies, it was shown that for metabolomic studies [reviewed in (140)] serum was detected to be superior with respect to sensitivity, but the use of plasma provided more reproducible results. Overall, variation induced by anticoagulation additives seems to be marginal; however, in a report of Hebels and colleagues, there is the strong recommendation that metabolomic studies should not mix plasma samples with different additives (112).

For generation of serum from whole blood, appropriate and uniform conditions for completion of the clotting procedure are mandatory [clotting period 30-60 min, temperature, type and concentration of additives as clotting enhancers, etc. (148)]. Use of tubes equipped with a gel barrier did not affect SP analyses on serum samples (143). Plasma preparation requires additives for prevention of coagulation such as EDTA, citrate, and fluoride, following standard procedures: centrifugal force 1.500 up to $4.000 \times \mathrm{g}$, temperature range $4-15^{\circ} \mathrm{C}$, centrifugation time 5$10 \mathrm{~min}$ [(148) and references cited therein]. In these conditions, however, those plasma specimen are not completely free from (activated) platelets, leading to differences in metabolic patterns obtained from plasma (140). Moreover, during storage these remaining platelets are lysed in an unspecific manner. Up to now, it is an open question, if and in which manner these debris from lysed platelets might cause known discrepancies in metabolomics studies with plasma as starting material (148). The only way out is preparation of platelet-free plasma by reduction of remained platelets $<10,000 / \mu \mathrm{L}$ (150) by increasing either the centrifugation time or the centrifugal force in a second separation step (151). There is one report stating the use of heparin results in higher variability with respect to SP (25).

Hemolytic samples should be completely withdrawn (or at any rate analyzed with caution) due to the facts of adverse effects on metabolomic studies $(152,153)$ and especially of inestimable but severe alterations of SP highly abundant in red blood cells (152).

The same is true for variation of handling (i) time [postprocessing $<2 \mathrm{~h}$. (153)], (ii) temperature profile, and (iii) centrifugal phase separation parameters (time force, shear stress) exposed to the drawn sample up to freezing $(146,154)$, all in all emphasizing the demand for a uniform procedure including a careful removal of the liquid phase without disturbing the particular fraction. As a consequence, consideration of the effects of pre-analytical factors is a particularly important issue for long-lasting studies, especially when samples are collected in decentralized settings with a risk of time and temperature delays prior to being completely processed and frozen for storage. Of note, preprocessing at room temperature before centrifugation might result in an increase of S1P signals (152). Prior and after PPP, the samples are stored regularly at least at $-80^{\circ} \mathrm{C}$, in large multicentric studies occasionally for years. Beyond quality 
indicators for pre-analytical process variations such as time to centrifugation (155), levels of 56 out of 111 metabolites (also degradation of SM-14.8\%) were reported in a five-year period of storage (156); the same was true for cholesterol and triglycerides (157). Thus, storage time has to be taken into account and a potential bias should be overcome by a smart batch management of samples. Also, the number of freeze-thaw cycles significantly affects a number of lipid mediators such as phosphatidylcholines (PC) and SM (25). However, other studies demonstrated minor changes but also oxidative modification of unsaturated fatty acids (100). As a consequence, the number of freeze/thaw cycles should be kept constant throughout the study, and sub-aliquoting helps to minimize possible artifacts (119).

From plasma samples, a purified platelet fraction can also be used for SP profiling; in a recent study in patients with coronary artery disease, a total of 39 SM and 23 Cer species were detected for detection of additional insights of mechanisms responsible for symptomatic thrombus formation during an acute myocardial infarction (158).

\section{Platelets, Microvesicles, and Exosomes}

Platelets have a short life span around 8 to 10 days in circulation and are activated during inflammation and infection; therefore, they function as an excellent reporting system during a variety of diseases. Moreover, activated platelets release platelet-derived microvesicles (PMV), often termed "platelet dust," playing both a pivotal role in atherosclerosis, thrombosis, and immune defense (159). The same is true in stored platelets, where the release of PMV is induced by senescence as a storage lesion (160). During storage, the content of ceramides significantly increased $(+53 \%)$ and S1P decreased $(-53 \%)$, all in all shifting SP metabolism toward Cer (161). The heterogeneous extracellular vesicles generated from platelets differ with respect to size, composition, and function (159). The same is true for plasmaborne exosomes, which are small vesicles released from cells and platelets after fusing of multivesicular bodies with the plasma membrane upon activation. Other types of extracellular vesicles are formed by direct budding of the membrane and are larger in size $(100-1,000 \mathrm{~nm}$, also termed microvesicles). Apoptotic bodies $(<2,000 \mathrm{~nm})$ are also formed by blebbing of membranes from cells undergoing apoptosis (162). Reported lipid compositions that are found to be enriched in these particles vary due to principles of cellular source and biogenesis, which has implications to functions as well as clinical applications as biomarkers and possible use for drug delivery (162). Especially, the majority of the blood-borne extracellular vesicles are thought to originate from either platelets or directly from the platelet precursor cell platelets, participating in a plethora of physiological functions, including hemostasis and immunity as well as in thrombogenesis $(159,163)$.

From plasma, the most commonly used method for isolation of exosomes is ultracentrifugation, but this procedure results in co-isolation of exosomes, lipoproteins, and lipid droplets (164). More sophisticated methods for isolation are filtration, size exclusion, or immune-affinity chromatography, all of them with advantages and disadvantages with respect to homogeneity and presence of related subpopulations of extracellular vesicles
(165-168). Thus, these factors should be taken into careful consideration interpreting results drawn from preparation of extracellular vesicles. As an example, the presence of cholesterol esters or triacylglycerol derivatives in your analyses, which are regularly not present in cellular membranes (46), supports the concept that lipoproteins or lipid droplets have been co-isolated with exosomes (162). On the other hand, immunological characterization of platelet-derived exosomes allowed improvement of the early detection of the infective agent in fungal sepsis (169). A short overview for preparation of subfractions of whole blood and the properties thereof is given in Figure 3. In contrast to oncological studies using these extracellular vesicles for improved diagnosis and therapeutical monitoring $(170,171)$, in translational sepsis research they are just often only recognized with respect to their pro-coagulant and pro-inflammatory function (172).

\section{Red Blood Cells}

Similar to platelets also red blood cells (RBC) during their short life span exhibit the closest contact toward every tissue and cells in the organism and might therefore act as a carrier of information upon exchange of SP following isolation. Since inhibition of SP biosynthesis in solid tissues affects their concentration levels in plasma as well in RBC (173), analyses of SP composition of RBC opens the field for studying changes in metabolic mechanisms in deep compartments without any access in routine diagnostics. Induced by a variety of causes (osmotic pressure, oxidative stress, energy depletion, etc.) and comparable to apoptosis of nucleated cells, also RBCs may undergo suicidal death characterized by cell shrinkage and phospholipid scrambling and redistribution of the cell membrane, termed eryptosis $(174,175)$. Whatever the rapid clearance of eryptotic $\mathrm{RBC}$, canonical mechanisms are held responsible to trigger eryptosis including formation of Cer, which might be observed by techniques of sphingolipidomics (176). Enhanced erythrocytic Cer formation was observed in fever, sepsis, hepatic failure, and metabolic diseases (177).

Recently, a specific transporter termed Mfsd2b with high S1P export capacity from platelets and RBC was identified, which is sensitive to stress (178). That susceptibility toward biomedical/pathophysiological factors but also toward handling of samples underlines the role of anucleated cells in S1P distribution, function, and metabolism.

\section{White Blood Cells}

Sphingolipids are also involved in leukocyte activation and reprogramming during sepsis $(179,180)$. The mixed cell population is isolated from whole blood samples using a simple and rapid centrifugation procedure based on a density gradient procedure developed by Bøyum (181, 182). For mass spectrometric analyses, contaminating platelets in the raw leukocyte fraction should be effectively removed by a second centrifugation step (183). Following cell counting, cellular proteins from a predefined number of pelleted cells are precipitated by addition of methanol and lysis of cells at low temperatures. 

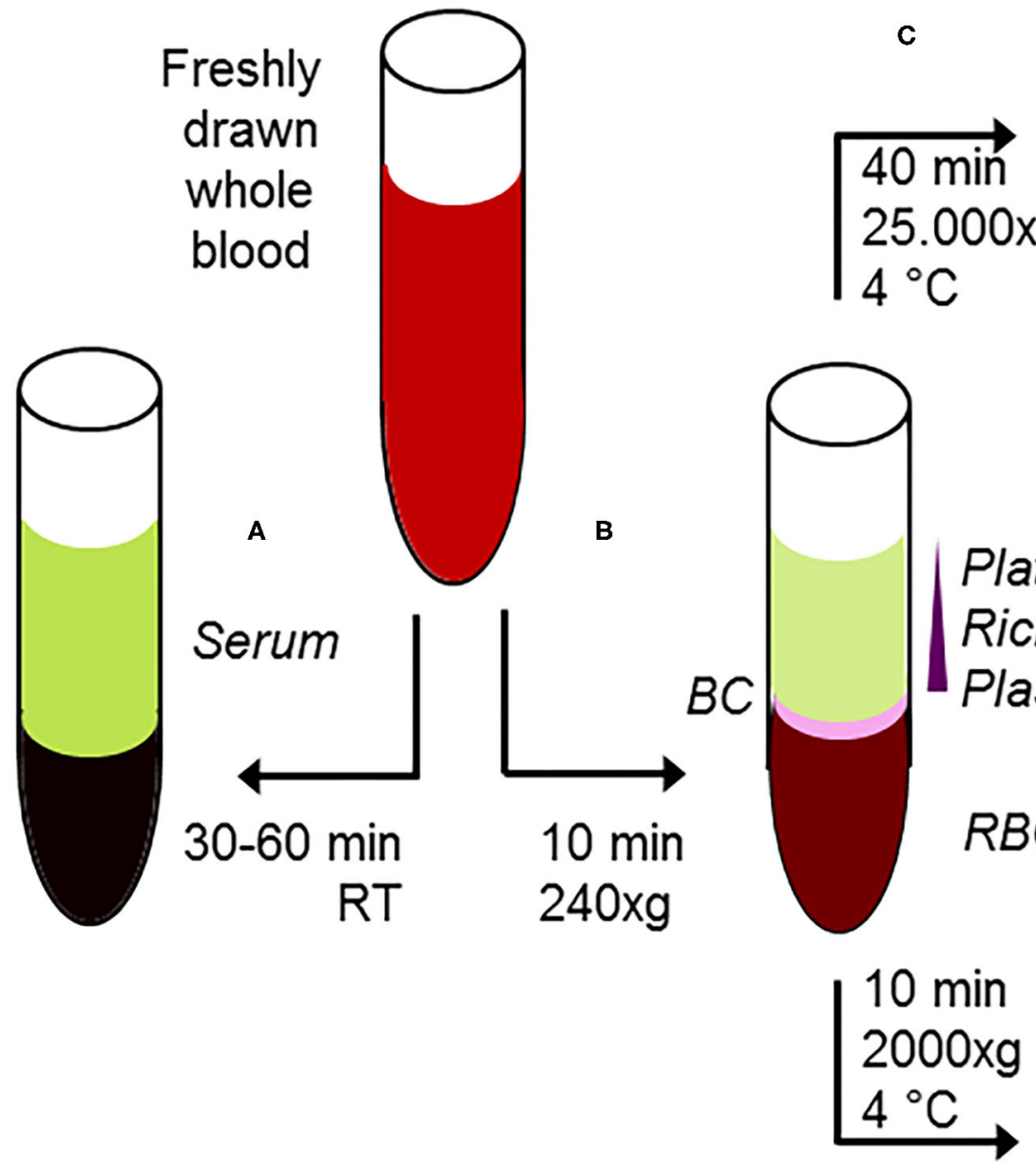

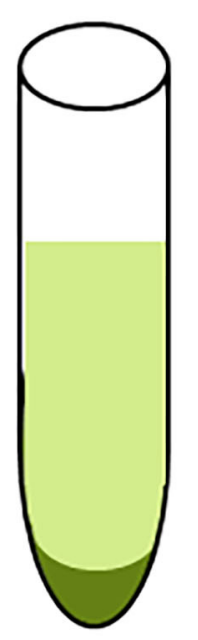

Plasma

with

exosomes

PMV

Platelet

Pure

Plasma

residual

platelet

leukocyte debris

FIGURE 3 | Classical protocol for preanalytical procedures of starting material. (A) After adding of clotting enhancers to freshly drawn blood and completion of clotting procedure 30-60 min, room temperature), serum samples are harvested following centrifugation. (B) Freshly drawn, anti-coagulated whole blood is briefly centrifuged at low centrifugal forces (softspin, $240 \times \mathrm{g}, 10 \mathrm{~min}$ ), resulting in separation of three layers: red blood cells $(\mathrm{RBC})$ at the bottom, a layer termed "buffy coat" (BC) of typically whitish color containing the major proportion of leucocytes, and some platelets in an intermediate layer and acellular, crude platelet-rich plasma fraction (PRP) with varying platelet contents. For further separation, the crude PRP layer is transferred to a fresh tube. After hard-spin centrifugation, most of the supernatant is harvested as the platelet-pure plasma fraction. The final PRP concentrate at the bottom consists of an undetermined fraction of BC (containing a large number of platelets) suspended in some fibrin-rich plasma. The transfer step is often performed with a syringe or pipette, with only visual inspection. Because the manual PPP process is not clearly defined, this protocol might randomly lead to impure plasma fractions. (C) From the PRP fraction, platelet-derived microvesicles (PMV) are isolated by centrifugation $(25.000 \times \mathrm{g} / 40 \mathrm{~min})$, and finally, plasma-borne exosomes can be obtained from the remaining supernatant. Using the buffy coat fraction for isolation of leukocytes, nucleated cells should be further purified by a second centrifugation step.

A series of studies-mainly carried out with cultured cells or with animal experiments-describe the formation of Cerenriched lipid rafts as highly dynamic molecular devices for receptor protein reorganization and subsequent signal transduction $(50,51)$. Ceramides and $\mathrm{S} 1 \mathrm{P}$ are also known as reciprocal modulators of cell survival and proliferation $(6,55)$. The increase of Cer following bacterial infection might be caused by SM breakdown (74). The activation of the enzyme responsible for conversion of SM to Cer (acid sphingomyelinase, SMPD1) is associated with maturation of the phagolysosome and intracellular degradation of pathogens (184) as well as severity of the underlying disease (185) and sensitive to anti-inflammatory therapy (186). Next, conversion of SM to Cer is involved in formation of neutrophil extracellular traps (187) and release of 
reactive oxygen species $(188,189)$. Subsequent degradation of ceramides results in the formation of sphingosine, an SP with remarkable antibacterial activity (81). Phosphorylation thereof is leading to S1P, a molecule with complex functions during infection ranging from cell activation to trafficking and tissue protection to mention a few [excellently reviewed in (83)]. More studies from this compartment are urgently needed for rigorous association and a better understanding of SP-triggered functions of leukocytes in human sepsis.

\section{Data Interpretation and Visualization}

Data sets obtained in metabolomic analyses are large and complex; thus, numerous algorithms and a strategy for data quality improvement are required. On the basis of the broad variation in rates of dissociation not only between SP subclasses but also in a particular class, absolute quantitation of SP using only precursor ion scan is not recommended. Here, relative comparison using MRM results and a corresponding internal standard compound for normalization is an appropriate approach (108). After picking the true peak of the lipid of interest by confirmation of the presence of co-eluting qualifier ormuch more specific by a precursor ion scan experiment-and determination of the areas of quantifier transitions by automated peak integration, data were normalized with corresponding, class specific internal standard compounds (190). Of note, in-source loss of hexoses of glycosylated ceramide derivatives results in an overlay with unglycosylated derivatives. It might be expected that glycosylated ceramide derivatives point out a shorter retention time with lower signal intensity.

Next, the set of raw data is subjected to filtering with the aims of $i$ / confirmation of minimal variations in retention time with stepwise increase in parallel with respect to increasing number of carbon atoms in the acyl chain, ii/ exclusion of potential artifacts, and iii/ definition of signal-to-noise $(\mathrm{S} / \mathrm{N})$ ratio especially to characterize low abundance SP with poor signals (quality control). Criteria for filtering are correlating with the specific aims and management of the study and should be fixed in advance, e.g., to exclude signals (= lipid species) with a $\mathrm{S} / \mathrm{N}$ ratio $<10$. Outliers should be defined and removed, and missing values can be carefully imputed (191). Quality samples (see above) will help to identify and to correct either drifts of the instrument (retention time, resolution of peaks, sensitivity) and/or batch effects. At the end, at least the implementation of a principal component analysis visualizes similarities or discrepancies of your sample groups in heatmaps including appropriate biostatistical univariate or multivariate approaches.

\section{CONCLUSIONS AND TAKE-HOME MESSAGES}

In translational sepsis research, generation and interpretation of data from human blood samples, either from the liquid or particular phase, using the approach of mass spectrometric analyses, opens the field of a better understanding of this complex and convoluted biological system. Whatever all interrelationships are understood in detail, these data will contribute further insights into the dark site of disease-associated signaling. We will be able to oversee a more complete picture of all interconversations of these molecules and biomarkers, even driven by host or pathogen proteins in a tightly regulated and highly dynamic process. Next, the approach will result in more elaborated pathways of the synergistic but also antagonistic properties of these compounds in the issue of life or death of a cell or of an organism. Association of the sphingolipidomic profile to a distinct phenotype will support this concept. Finally, this procedure is without any alternative to discover the action, relationships, and mechanism of potential drugs in a complex disease, especially with respect to a more personalized treatment approach in the future.

- Structural diversity of sphingolipids is the key feature of underlying pleiotropic effects.

- Sphingolipids are ubiquitously distributed biomolecules participating in membrane organization, barrier function, metabolism, and signaling to stress in every known eukaryotic cell type.

- The integration of a targeted metabolomic approach as an information-rich analytical platform can provide important insight into health as well as mechanisms and diagnosis of disease and therapy (theranostic).

- Analyzing the generation and the dynamic of sphingolipids during severe infection and sepsis in different compartments will result in a better understanding of pathogenesis and risk assessment.

- For these aims, targeted and sophisticated experimental settings are critical, starting from sample preparation and storage, analysis, processing up to data interpretation.

- Future efforts are needed for more advanced analysis tools of such datasets.

\section{AUTHOR CONTRIBUTIONS}

$\mathrm{RC}$ drafted the manuscript. Both authors revised the final version of the manuscript.

\section{FUNDING}

This work was supported by internal institutional funds from the Department of Anesthesiology and Intensive Care Medicine, Jena University Hospital, Germany.

\section{DEDICATION}

The manuscript is dedicated to the memory of Ms. Susann Hoffmann (1985 - 2020), a member of our group analyzing sphingolipid composition of plasma proteins in health and disease.

\section{ACKNOWLEDGMENTS}

We grateful appreciate valuable suggestions and helpful comments of Ms. Tina Müller and Nadine Krieg, Ph.D., when critically reading the manuscript. 


\section{REFERENCES}

1. Merrill AH Jr, Sullards MC, Allegood JC, Kelly S, Wang E, et al. Sphingolipidomics: high-throughput, structure-specific, and quantitative analysis of sphingolipids by liquid chromatography tandem mass spectrometry. Methods. (2005) 36:207-24. doi: 10.1016/j.ymeth.2005.01.009

2. Pruett ST, Bushnev A, Hagedorn K, Adiga M, Haynes CA, Sullards MC, et al. Biodiversity of sphingoid bases ("sphingosines") and related amino alcohols. J Lipid Res. (2008) 49:1621-39. doi: 10.1194/jlr.R800012-JLR200

3. Fahy E, Subramaniam S, Murphy RC, Nishijima M, Raetz CR, Shimizu T, et al. Update of the LIPID MAPS comprehensive classification system for lipids. J Lipid Res. (2009) 50:S9-14. doi: 10.1194/jlr.R800095-JLR200

4. Liebisch G, Fahy E, Aoki J, Dennis EA, Durand T, Ejsing C, et al. Update on LIPID MAPS classification, nomenclature and shorthand notation for ms-derived lipid structures. J Lipid Res. (2020) 61:153955. doi: 10.1194/jlr.S120001025

5. Berwick ML, Dudley BA, Maus K, Chalfant CE. The role of ceramide 1phosphate in inflammation, cellular proliferation, and wound healing. $A d v$ Exp Med Biol. (2019) 1159:65-77. doi: 10.1007/978-3-030-21162-2_5

6. Hannun YA, Obeid LM. Sphingolipids and their metabolism in physiology and disease. Nat Rev Mol Cell Biol. (2018) 19:175-91. doi: 10.1038/nrm.2017.107

7. Zheng W, Kollmeyer J, Symolon H, Momin A, Munter E, Wang E, et al. Ceramides and other bioactive sphingolipid backbones in health and disease: lipidomic analysis, metabolism and roles in membrane structure, dynamics, signaling and autophagy. Biochim Biophys Acta. (2006) 1758:1864-84. doi: 10.1016/j.bbamem.2006.08.009

8. Bartke N, Hannun YA. Bioactive sphingolipids: metabolism and function. $J$ Lipid Res. (2009) 50 Suppl:S91-6. doi: 10.1194/jlr.R800080-JLR200

9. Manni MM, Sot J, Arretxe E, Gil-Redondo R, Falcon-Perez JM, Balgoma D, et al. The fatty acids of sphingomyelins and ceramides in mammalian tissues and cultured cells: biophysical and physiological implications. Chem Phys Lipids. (2018) 217:29-34. doi: 10.1016/j.chemphyslip.2018.09.010

10. Quehenberger O, Armando AM, Brown AH, Milne SB, Myers DS, Merrill $\mathrm{AH}$, et al. Lipidomics reveals a remarkable diversity of lipids in human plasma. J Lipid Res. (2010) 51:3299-305. doi: 10.1194/jlr.M009449

11. t'Kindt R, Jorge L, Dumont E, Couturon P, David F, Sandra P, et al. Profiling and characterizing skin ceramides using reversed-phase liquid chromatography-quadrupole time-of-flight mass spectrometry. Anal Chem. (2012) 84:403-11. doi: 10.1021/ac202646v

12. Kihara Y, Maceyka M, Spiegel S, Chun J. Lysophospholipid receptor nomenclature review: IUPHAR review 8. Br J Pharmacol. (2014) 171:357594. doi: 10.1111/bph.12678

13. Takuwa Y, Okamoto Y, Yoshioka K, Takuwa N. Sphingosine-1phosphate signaling in physiology and diseases. Biofactors. (2012) 38:329-37. doi: 10.1002/biof.1030

14. Brindley DN, Pilquil C. Lipid phosphate phosphatases and signaling. J Lipid Res. (2009) 50(Suppl):S225-30. doi: 10.1194/jlr.R800055-JLR200

15. Ksiazek M, Chacinska M, Chabowski A, Baranowski M. Sources, metabolism, and regulation of circulating sphingosine-1-phosphate. J Lipid Res. (2015) 56:1271-81. doi: 10.1194/jlr.R059543

16. Regina Todeschini A, Hakomori SI. Functional role of glycosphingolipids and gangliosides in control of cell adhesion, motility, and growth, through glycosynaptic microdomains. Biochim Biophys Acta. (2008) 1780:42133. doi: 10.1016/j.bbagen.2007.10.008

17. Wennekes $T$, van den Berg RJ, Boot RG, van der Marel GA, Overkleeft HS, Aerts JM. Glycosphingolipids-nature, function, and pharmacological modulation. Angew Chem Int Ed Engl. (2009) 48:8848-69. doi: 10.1002/anie.200902620

18. Hakomori SI. Structure and function of glycosphingolipids and sphingolipids: recollections and future trends. Biochim Biophys Acta. (2008) 1780:325-46. doi: 10.1016/j.bbagen.2007.08.015

19. Iqbal J, Walsh MT, Hammad SM, Hussain MM. Sphingolipids and lipoproteins in health and metabolic disorders. Trends Endocrinol Metabol. (2017) 28:506-18. doi: 10.1016/j.tem.2017.03.005

20. Sandhoff R, Sandhoff, K. Emerging concepts of ganglioside metabolism. FEBS Lett. (2018) 592:3835-64. doi: 10.1002/1873-3468.13114
21. Ferreira CR, Gahl WA. Lysosomal storage diseases. Transl Sci Rare Dis. (2017) 2:1-71. doi: 10.3233/TRD-160005

22. Lone MA, Santos T, Alecu I, Silva LC, Hornemann T. 1Deoxysphingolipids. Biochim Biophys Acta Mol Cell Biol Lipids. (2019) 1864:512-21. doi: 10.1016/j.bbalip.2018.12.013

23. Alecu I, Tedeschi A, Behler N, Wunderling K, Lamberz C, Lauterbach MA, et al. Localization of 1-deoxysphingolipids to mitochondria induces mitochondrial dysfunction. J Lipid Res. (2017) 58:42-59. doi: 10.1194/jlr.M068676

24. Ellis SR, Brown SH, In Het Panhuis M, Blanksby SJ, Mitchell TW. Surface analysis of lipids by mass spectrometry: more than just imaging. Prog Lipid Res. (2013) 52:329-53. doi: 10.1016/j.plipres.2013.04.005

25. Hammad SM, Pierce JS, Soodavar F, Smith KJ, Al Gadban MM, Rembiesa B, et al. Blood sphingolipidomics in healthy humans: impact of sample collection methodology. J Lipid Res. (2010) 51:3074-87. doi: 10.1194/jlr.D008532

26. Scherer M, Bottcher A, Schmitz G, Liebisch G. Sphingolipid profiling of human plasma and FPLC-separated lipoprotein fractions by hydrophilic interaction chromatography tandem mass spectrometry. Biochim Biophys Acta. (2011) 1811:68-75. doi: 10.1016/j.bbalip.2010.11.003

27. Daum G, Winkler M, Moritz E, Muller T, Geffken M, von Lucadou $\mathrm{M}$, et al. Determinants of serum- and plasma sphingosine-1-phosphate concentrations in a healthy study group. TH Open. (2020) 4:e12e9. doi: 10.1055/s-0040-1701205

28. Hammad SM, Al Gadban MM, Semler AJ, Klein RL. Sphingosine 1phosphate distribution in human plasma: associations with lipid profiles. $J$ Lipids. (2012) 2012:180705. doi: 10.1155/2012/180705

29. Narayanaswamy P, Shinde S, Sulc R, Kraut R, Staples G, Thiam CH, et al. Lipidomic "deep profiling": an enhanced workflow to reveal new molecular species of signaling lipids. Anal Chem. (2014) 86:30437. doi: $10.1021 /$ ac4039652

30. Wong MWK, Braidy N, Pickford R, Vafaee F, Crawford J, Muenchhoff J, et al. Plasma lipidome variation during the second half of the human lifespan is associated with age and sex but minimally with BMI. PLoS ONE. (2019) 14:e0214141. doi: 10.1371/journal.pone.0214141

31. Maia LP, Santos PS, Alves PT, Rodrigues CM, Araujo TG, Maia YCP, et al. Altered leukocyte sphingolipid pathway in breast cancer. Int J Mol Sci. (2017) 18:2521. doi: 10.3390/ijms18122521

32. de Figueiredo Junior AG, Serafim PVP, de Melo AA, Felipe AV, Lo Turco EG, da Silva I, et al. Analysis of the lipid profile in patients with colorectal cancer in advanced stages. Asian Pac J Cancer Prev. (2018) 19:128793. doi: 10.22034/APJCP.2018.19.5.1287

33. Meshcheryakova A, Svoboda M, Jaritz M, Mungenast F, Salzmann M, Pils $\mathrm{D}$, et al. Interrelations of sphingolipid and lysophosphatidate signaling with immune system in ovarian cancer. Comput Struct Biotechnol J. (2019) 17:537-60. doi: 10.1016/j.csbj.2019.04.004

34. Lee JW, Mok HJ, Lee DY, Park SC, Kim GS, Lee SE, et al. UPLC-QqQ/MS-based lipidomics approach to characterize lipid alterations in inflammatory macrophages. J Proteome Res. (2017) 16:1460-9. doi: 10.1021/acs.jproteome.6b00848

35. Andreyev AY, Fahy E, Guan Z, Kelly S, Li X, McDonald JG, et al. Subcellular organelle lipidomics in TLR-4-activated macrophages. J Lipid Res. (2010) 51:2785-97. doi: 10.1194/jlr.M008748

36. Gorden DL, Myers DS, Ivanova PT, Fahy E, Maurya MR, Gupta S, et al. Biomarkers of NAFLD progression: a lipidomics approach to an epidemic. J Lipid Res. (2015) 56:722-36. doi: 10.1194/jlr.P056002

37. Chung HY, Witt CJ, Jbeily N, Hurtado-Oliveros J, Giszas B, Lupp A, et al. Acid sphingomyelinase inhibition prevents development of sepsis sequelae in the murine liver. Sci Rep. (2017) 7:12348. doi: 10.1038/s41598-017-11837-2

38. Bezgovsek J, Gulbins E, Friedrich SK, Lang KS, Duhan V. Sphingolipids in early viral replication and innate immune activation. Biol Chem. (2018) 399:1115-23. doi: 10.1515/hsz-2018-0181

39. Alonso A, Goni FM. The physical properties of ceramides in membranes. Annu Rev Biophys. (2018) 47:63354. doi: 10.1146/annurev-biophys-070317-033309

40. Patel DS, Park S, Wu EL, Yeom MS, Widmalm G, Klauda JB, et al. Influence of ganglioside gm1 concentration on lipid clustering 
and membrane properties and curvature. Biophys J. (2016) 111:198799. doi: 10.1016/j.bpj.2016.09.021

41. Verderio C, Gabrielli M, Giussani P. Role of sphingolipids in the biogenesis and biological activity of extracellular vesicles. J Lipid Res. (2018) 59:132540. doi: 10.1194/jlr.R083915

42. Lingwood D, Simons, K. Lipid rafts as a membrane-organizing principle. Science. (2010) 327:46-50. doi: 10.1126/science.1174621

43. Ait Slimane T, Hoekstra D. Sphingolipid trafficking and protein sorting in epithelial cells. FEBS Lett. (2002) 529:549. doi: 10.1016/S0014-5793(02)03183-6

44. Lopez PH, Schnaar RL. Gangliosides in cell recognition and membrane protein regulation. Curr Opin Struct Biol. (2009) 19:549-57. doi: 10.1016/j.sbi.2009.06.001

45. Lopez PH, Schnaar RL. Determination of glycolipid-protein interaction specificity. Methods Enzymol. (2006) 417:20520. doi: 10.1016/S0076-6879(06)17015-9

46. van Meer G, Voelker DR, Feigenson GW. Membrane lipids: where they are and how they behave. Nat Rev Mol Cell Biol. (2008) 9:11224. doi: $10.1038 / \mathrm{nrm} 2330$

47. Kiessling V, Yang ST, Tamm LK. Supported lipid bilayers as models for studying membrane domains. Curr Top Membr. (2015) 75:123. doi: 10.1016/bs.ctm.2015.03.001

48. Nickels JD, Smith JC, Cheng X. Lateral organization, bilayer asymmetry, and inter-leaflet coupling of biological membranes. Chem Phys Lipids. (2015) 192:87-99. doi: 10.1016/j.chemphyslip.2015.07.012

49. Castro BM, Prieto M, Silva LC. Ceramide: a simple sphingolipid with unique biophysical properties. Prog Lipid Res. (2014) 54:5367. doi: 10.1016/j.plipres.2014.01.004

50. Bieberich, E. Sphingolipids and lipid rafts: novel concepts and methods of analysis. Chem Phys Lipids. (2018) 216:11431. doi: 10.1016/j.chemphyslip.2018.08.003

51. Ernst AM, Brugger B. Sphingolipids as modulators of membrane proteins. Biochim Biophys Acta. (2014) 1841:665-70. doi: 10.1016/j.bbalip.2013.10.016

52. Leonard C, Conrard L, Guthmann M, Pollet H, Carquin M, Vermylen C, et al. Contribution of plasma membrane lipid domains to red blood cell (re)shaping. Sci Rep. (2017) 7:4264. doi: 10.1038/s41598-017-04388-Z

53. Peng B, Geue S, Coman C, Munzer P, Kopczynski D, Has C, et al. Identification of key lipids critical for platelet activation by comprehensive analysis of the platelet lipidome. Blood. (2018) 132:e1-e12. doi: 10.1182/blood-2017-12-822890

54. Maceyka M, Spiegel, S. Sphingolipid metabolites in inflammatory disease. Nature. (2014) 510:58-67. doi: 10.1038/nature 13475

55. Hait NC, Maiti A. The role of sphingosine-1-phosphate and ceramide1-phosphate in inflammation and cancer. Mediators Inflamm. (2017) 2017:4806541. doi: 10.1155/2017/4806541

56. Matloubian M, Lo CG, Cinamon G, Lesneski MJ, Xu Y, Brinkmann $\mathrm{V}$, et al. Lymphocyte egress from thymus and peripheral lymphoid organs is dependent on S1P receptor 1. Nature. (2004) 427:35560. doi: $10.1038 /$ nature 02284

57. Sattler K, Lehmann I, Graler M, Brocker-Preuss M, Erbel R, Heusch G, et al. HDL-bound sphingosine 1-phosphate (S1P) predicts the severity of coronary artery atherosclerosis. Cell Physiol Biochem. (2014) 34:17284. doi: 10.1159/000362993

58. Alshaker H, Thrower H, Pchejetski D. Sphingosine kinase 1 in breast cancer-a new molecular marker and a therapy target. Front Oncol. (2020) 10:289. doi: 10.3389/fonc.2020.00289

59. Meikle PJ, Summers SA. Sphingolipids and phospholipids in insulin resistance and related metabolic disorders. Nat Rev Endocrinol. (2017) 13:7991. doi: $10.1038 /$ nrendo. 2016.169

60. Fucho R, Casals N, Serra D, Herrero L. Ceramides and mitochondrial fatty acid oxidation in obesity. FASEB J. (2017) 31:1263-72. doi: 10.1096/fj.201601156R

61. Montefusco DJ, Allegood JC, Spiegel S, Cowart LA. Non-alcoholic fatty liver disease: insights from sphingolipidomics. Biochem Biophys Res Commun. (2018) 504:608-16. doi: 10.1016/j.bbrc.2018.05.078

62. Simon J, Ouro A, Ala-Ibanibo L, Presa N, Delgado TC, MartinezChantar ML. Sphingolipids in non-alcoholic fatty liver disease and hepatocellular carcinoma: ceramide turnover. Int J Mol Sci. (2019) 21:40. doi: $10.3390 / \mathrm{ijms} 21010040$

63. Sui J, He M, Wang Y, Zhao X, He Y, Shi B, et al. Sphingolipid metabolism in type 2 diabetes and associated cardiovascular complications. Exp Ther Med. (2019) 18:3603-14. doi: 10.3892/etm.2019.7981

64. Kulakowska A, Zendzian-Piotrowska M, Baranowski M, Kononczuk T, Drozdowski W, Gorski J, et al. Intrathecal increase of sphingosine 1phosphate at early stage multiple sclerosis. Neurosci Lett. (2010) 477:14952. doi: 10.1016/j.neulet.2010.04.052

65. Halmer R, Walter S, Fassbender, K. Sphingolipids: important players in multiple sclerosis. Cell Physiol Biochem. (2014) 34:111-8. doi: 10.1159/000362988

66. Chakrabarti SS, Bir A, Poddar J, Sinha M, Ganguly A, Chakrabarti S, et al. Ceramide and sphingosine-1-phosphate in cell death pathways : relevance to the pathogenesis of alzheimer's disease. Curr Alzheimer Res. (2016) 13:123248. doi: 10.2174/1567205013666160603004239

67. Martinez PM, Mielke MM. Sphingolipids in alzheimer's disease and related disorders. J Alzheimers Dis. (2017) 60:753-6. doi: 10.3233/JAD-170735

68. Mohamud Yusuf A, Hagemann N, Hermann DM. The acid sphingomyelinase/ ceramide system as target for ischemic stroke therapies. NeuroSignals. (2019) 27:32-43. doi: 10.33594/000000184

69. Sun N, Keep RF, Hua Y, Xi, G. Critical role of the sphingolipid pathway in stroke: a review of current utility and potential therapeutic targets. Transl Stroke Res. (2016) 7:420-38. doi: 10.1007/s12975-016-0477-3

70. Trayssac M, Hannun YA, Obeid LM. Role of sphingolipids in senescence: implication in aging and age-related diseases. J Clin Invest. (2018) 128:270212. doi: 10.1172/JCI97949

71. Meeusen JW, Donato LJ, Bryant SC, Baudhuin LM, Berger PB, Jaffe AS. Plasma ceramides. Arterioscler Thromb Vasc Biol. (2018) 38:19339. doi: 10.1161/ATVBAHA.118.311199

72. Singer M, Deutschman CS, Seymour CW, Shankar-Hari M, Annane D, Bauer $\mathrm{M}$, et al. The third international consensus definitions for sepsis and septic shock (Sepsis-3). JAMA. (2016) 315:801-10. doi: 10.1001/jama.2016.0287

73. Heung LJ, Luberto C, Del Poeta M. Role of sphingolipids in microbial pathogenesis. Infect Immun. (2006) 74:2839. doi: 10.1128/IAI.74.1.28-39.2006

74. Li C, Wang A, Wu Y, Gulbins E, Grassme H, Zhao Z, et al. Acid sphingomyelinase-ceramide system in bacterial infections. Cell Physiol Biochem. (2019) 52:280-301. doi: 10.33594/000000021

75. Claus R, Russwurm S, Meisner M, Kinscherf R, Deigner HP. Modulation of the ceramide level, a novel therapeutic concept? Curr Drug Targets. (2000) 1:185-205. doi: 10.2174/1389450003349272

76. Claus RA, Dorer MJ, Bunck AC, Deigner HP. Inhibition of sphingomyelin hydrolysis: targeting the lipid mediator ceramide as a key regulator of cellular fate. Curr Med Chem. (2009) 16:1978-2000. doi: 10.2174/092986709788682182

77. Ma J, Gulbins E, Edwards MJ, Caldwell CC, Fraunholz M, Becker KA. Staphylococcus aureus alpha-toxin induces inflammatory cytokines via lysosomal acid sphingomyelinase and ceramides. Cell Physiol Biochem. (2017) 43:2170-84. doi: 10.1159/000484296

78. Rolando M, Escoll P, Nora T, Botti J, Boitez V, Bedia C, et al. Legionella pneumophila S1P-lyase targets host sphingolipid metabolism and restrains autophagy. Proc Natl Acad Sci USA. (2016) 113:19016. doi: 10.1073/pnas.1522067113

79. Sharma L, Prakash H. Sphingolipids are dual specific drug targets for the management of pulmonary infections: perspective. Front Immunol. (2017) 8:378. doi: $10.3389 /$ fimmu. 2017.00378

80. Carstens H, Schumacher F, Keitsch S, Kramer M, Kuhn C, Sehl C, et al. Clinical development of sphingosine as anti-bacterial drug: inhalation of sphingosine in mini pigs has no adverse side effects. Cell Physiol Biochem. (2019) 53:1015-28. doi: 10.33594/000000194

81. Martin GE, Boudreau RM, Couch C, Becker KA, Edwards MJ, Caldwell CC, et al. Sphingosine's role in epithelial host defense: a natural antimicrobial and novel therapeutic. Biochimie. (2017) 141:91-6. doi: 10.1016/j.biochi.2017.03.014

82. Weigel C, Huttner SS, Ludwig K, Krieg N, Hofmann S, Schroder $\mathrm{NH}$, et al. S1P lyase inhibition protects against sepsis by promoting 
disease tolerance via the S1P/S1PR3 axis. EBioMedicine 58:102898. doi: 10.1016/j.ebiom.2020.102898

83. Winkler MS, Nierhaus A, Poppe A, Greiwe G, Graler MH, Daum, et al. Sphingosine-1-Phosphate: a potential biomarker and therapeutic target for endothelial dysfunction and sepsis? Shock. (2017) 47:66672. doi: $10.1097 /$ SHK.0000000000000814

84. Winkler MS, Nierhaus A, Holzmann M, Mudersbach E, Bauer A, Robbe L, et al. Decreased serum concentrations of sphingosine-1-phosphate in sepsis. Crit Care. (2015) 19:372. doi: 10.1186/s13054-015-1089-0

85. Winkler MS, Martz KB, Nierhaus A, Daum G, Schwedhelm E, Kluge S, et al. Loss of sphingosine 1-phosphate (S1P) in septic shock is predominantly caused by decreased levels of high-density lipoproteins (HDL). J Intensive Care. (2019) 7:23. doi: 10.1186/s40560-019-0376-2

86. Neugebauer S, Giamarellos-Bourboulis EJ, Pelekanou A, Marioli A, Baziaka F, Tsangaris I, et al. Metabolite profiles in sepsis: developing prognostic tools based on the type of infection. Crit Care Med. (2016) 44:164962. doi: $10.1097 /$ CCM.0000000000001740

87. Hsu SC, Chang JH, Hsu YP, Bai KJ, Huang SK, Hsu CW. Circulating sphingosine-1-phosphate as a prognostic biomarker for community-acquired pneumonia. PLoS ONE. (2019) 14:e0216963. doi: 10.1371/journal.pone.0216963

88. To KK, Lee KC, Wong SS, Sze KH, Ke YH, Lui YM, et al. Lipid metabolites as potential diagnostic and prognostic biomarkers for acute community acquired pneumonia. Diagn Microbiol Infect Dis. (2016) 85:24954. doi: 10.1016/j.diagmicrobio.2016.03.012

89. Baumgartner T, Zurauskaite G, Steuer C, Bernasconi L, Huber A, Mueller B, et al. Association of serum sphingomyelin profile with clinical outcomes in patients with lower respiratory tract infections: results of an observational, prospective 6-year follow-up study. Clin Chem Lab Med. (2019) 57:67989. doi: $10.1515 / \mathrm{cclm}-2018-0509$

90. Song JW, Lam SM, Fan X, Cao WJ, Wang SY, Tian H, et al. Omics-driven systems interrogation of metabolic dysregulation in covid-19 pathogenesis. Cell Metab. (2020) 32:188-202.e185. doi: 10.1016/j.cmet.2020.06.016

91. Cui L, Lee YH, Kumar Y, Xu F, Lu K, Ooi EE, et al. Serum metabolome and lipidome changes in adult patients with primary dengue infection. PLoS Negl Trop Dis. (2013) 7:e2373. doi: 10.1371/journal.pntd.0002373

92. Inoue $\mathrm{S}$, Sakamoto $\mathrm{Y}$, Koami H, Yamada CK, Nagashima F, Miike T, et al. Sphingosine-1-Phosphate (S1P) is a feasible biomarker in predicting the efficacy of polymyxin B-immobilized fiber direct hemoperfusion (PMXDHP) in patients with septic shock. J Nippon Med Sch. (2018) 85:3946. doi: 10.1272 /jnms.2018_85-6

93. Ghidoni R, Caretti A, Signorelli, P. Role of sphingolipids in the pathobiology of lung inflammation. Mediators Inflamm. (2015) 2015:487508. doi: 10.1155/2015/487508

94. Ning P, Zheng Y, Luo Q, Liu X, Kang Y, Zhang Y, et al. Metabolic profiles in community-acquired pneumonia: developing assessment tools for disease severity. Crit Care. (2018) 22:130. doi: 10.1186/s13054-018-2049-2

95. Arshad H, Alfonso JCL, Franke R, Michaelis K, Araujo L, Habib A, et al. Decreased plasma phospholipid concentrations and increased acid sphingomyelinase activity are accurate biomarkers for community-acquired pneumonia. J Transl Med. (2019) 17:365. doi: 10.1186/s12967-019-2112-z

96. Marfia G, Navone S, Guarnaccia L, Campanella R, Mondoni M, Locatelli $M$, et al. Decreased serum level of sphingosine-1-phosphate: a novel predictor of clinical severity in COVID-19. EMBO Mol Med. (2020) 14:e13424. doi: 10.15252/emmm.202013424

97. Martin-Acebes MA, Gabande-Rodriguez E, Garcia-Cabrero AM, Sanchez MP, Ledesma MD, Sobrino F, et al. Host sphingomyelin increases west nile virus infection in vivo. J Lipid Res. (2016) 57:422-32. doi: 10.1194/jlr.M064212

98. Jiang X, Cheng H, Yang K, Gross RW, Han X. Alkaline methanolysis of lipid extracts extends shotgun lipidomics analyses to the lowabundance regime of cellular sphingolipids. Anal Biochem. (2007) 371:13545. doi: 10.1016/j.ab.2007.08.019

99. Han X, Cheng H. Characterization and direct quantitation of cerebroside molecular species from lipid extracts by shotgun lipidomics. J Lipid Res. (2005) 46:163-75. doi: 10.1194/jlr.D400022-JLR200

100. Surma MA, Herzog R, Vasilj A, Klose C, Christinat N, Morin-Rivron D, et al. An automated shotgun lipidomics platform for high throughput, comprehensive, and quantitative analysis of blood plasma intact lipids. Eur $J$ Lipid Sci Technol. (2015) 117:1540-9. doi: 10.1002/ejlt.201500145

101. Eggers LF, Schwudke D. Shotgun lipidomics approach for clinical samples. Methods Mol Biol. (2018) 1730:163-74. doi: 10.1007/978-1-4939-7592-1_12

102. Fhaner CJ, Liu S, Ji H, Simpson RJ, Reid GE. Comprehensive lipidome profiling of isogenic primary and metastatic colon adenocarcinoma cell lines. Anal Chem. (2012) 84:8917-26. doi: 10.1021/ac302154g

103. Peng B, Weintraub ST, Coman C, Ponnaiyan S, Sharma R, Tews $\mathrm{B}$, et al. A comprehensive high-resolution targeted workflow for the deep profiling of sphingolipids. Anal Chem. (2017) 89:12480-7. doi: 10.1021/acs.analchem.7b03576

104. Han X, Jiang X. A review of lipidomic technologies applicable to sphingolipidomics and their relevant applications. Eur J Lipid Sci Technol. (2009) 111:39-52. doi: 10.1002/ejlt.200800117

105. Sullards MC, Allegood JC, Kelly S, Wang E, Haynes CA, Park $\mathrm{H}$, et al. Structure-specific, quantitative methods for analysis of sphingolipids by liquid chromatography-tandem mass spectrometry: "inside-out" sphingolipidomics. Methods Enzymol. (2007) 432:83-115. doi: 10.1016/S0076-6879(07)32004-1

106. Farwanah H, Kolter T, Sandhoff K. Mass spectrometric analysis of neutral sphingolipids: methods, applications, and limitations. Biochim Biophys Acta. (2011) 1811:854-60. doi: 10.1016/j.bbalip.2011.05.011

107. Sullards MC, Merrill AH Jr. Analysis of sphingosine 1-phosphate, ceramides, and other bioactive sphingolipids by high-performance liquid chromatography-tandem mass spectrometry. Sci STKE. (2001) 2001:pl1. doi: 10.1126/stke.2001.67.pl1

108. Burla B, Muralidharan S, Wenk MR, Torta, F. Sphingolipid analysis in clinical research. Methods Mol Biol. (2018) 1730:13562. doi: 10.1007/978-1-4939-7592-1_11

109. Farwanah H, Wirtz J, Kolter T, Raith K, Neubert RH, Sandhoff K, et al. Normal phase liquid chromatography coupled to quadrupole time of flight atmospheric pressure chemical ionization mass spectrometry for separation, detection and mass spectrometric profiling of neutral sphingolipids and cholesterol. J Chromatogr. (2009) 877:2976-82. doi: 10.1016/j.jchromb.2009.07.008

110. Delatour T, Mottier P, Gremaud E. Limits of suspicion, recognition and confirmation as concepts that account for the confirmation transitions at the detection limit for quantification by liquid chromatography-tandem mass spectrometry. J Chromatogr A. (2007) 1169:103-10. doi: 10.1016/j.chroma.2007.08.065

111. Theodoridis GA, Gika HG, Want EJ, Wilson ID. Liquid chromatographymass spectrometry based global metabolite profiling: a review. Anal Chim Acta. (2012) 711:7-16. doi: 10.1016/j.aca.2011.09.042

112. Hebels DG, Georgiadis P, Keun HC, Athersuch TJ, Vineis P, Vermeulen $\mathrm{R}$, et al. Performance in omics analyses of blood samples in longterm storage: opportunities for the exploitation of existing biobanks in environmental health research. Environ Health Perspect. (2013) 121:4807. doi: 10.1289/ehp.1205657

113. Folch J, Lees M, Sloane Stanley GH. A simple method for the isolation and purification of total lipides from animal tissues. J Biol Chem. (1957) 226:497509.

114. Bligh EG, Dyer WJ. A rapid method of total lipid extraction and purification. Can J Biochem Physiol. (1959) 37:911-7. doi: 10.1139/y59-099

115. Dettmer K, Nurnberger N, Kaspar H, Gruber MA, Almstetter MF, Oefner PJ. Metabolite extraction from adherently growing mammalian cells for metabolomics studies: optimization of harvesting and extraction protocols. Anal Bioanal Chem. (2011) 399:1127-39. doi: 10.1007/s00216-010-4425-x

116. Ulmer CZ, Jones CM, Yost RA, Garrett TJ, Bowden JA. Optimization of folch, bligh-dyer, and matyash sample-to-extraction solvent ratios for human plasma-based lipidomics studies. Anal Chim Acta. (2018) 1037:3517. doi: $10.1016 /$ j.aca.2018.08.004

117. Lofgren L, Forsberg GB, Stahlman M. The BUME method: a new rapid and simple chloroform-free method for total lipid extraction of animal tissue. Sci Rep. (2016) 6:27688. doi: 10.1038/srep27688

118. Alshehry ZH, Barlow CK, Weir JM, Zhou Y, McConville MJ, Meikle PJ. An efficient single phase method for the extraction of plasma lipids. Metabolites. (2015) 5:389-403. doi: 10.3390/metabo5 020389 
119. Want EJ, Wilson ID, Gika H, Theodoridis G, Plumb RS, Shockcor J, et al. Global metabolic profiling procedures for urine using UPLC-MS. Nat Protoc. (2010) 5:1005-18. doi: 10.1038/nprot.2010.50

120. Zhao W, Weng Y. A simplified formula for quantification of the probability of deterministic assignments in permuted block randomization. J Stat Plan Inference. (2011) 141:474-8. doi: 10.1016/j.jspi.2010.06.023

121. Sangster T, Major H, Plumb R, Wilson AJ, Wilson ID. A pragmatic and readily implemented quality control strategy for HPLCMS and GC-MS-based metabonomic analysis. Analyst. (2006) 131:1075-8. doi: 10.1039/b604498k

122. Gika HG, Zisi C, Theodoridis G, Wilson ID. Protocol for quality control in metabolic profiling of biological fluids by U(H)PLC-MS. J Chromatogr. (2016) 1008:15-25. doi: 10.1016/j.jchromb.2015.10.045

123. Chew WS, Seow WL, Chong JR, Lai MKP, Torta F, Wenk MR, et al. Sphingolipidomics analysis of large clinical cohorts. Part 1: technical notes and practical considerations. Biochem Biophys Res Commun. (2018) 504:596601. doi: 10.1016/j.bbrc.2018.04.076

124. Burla B, Arita M, Arita M, Bendt AK, Cazenave-Gassiot A, Dennis EA, et al. MS-based lipidomics of human blood plasma: a community-initiated position paper to develop accepted guidelines. J Lipid Res. (2018) 59:200117. doi: 10.1194/jlr.S087163

125. Bowden JA, Heckert A, Ulmer CZ, Jones CM, Koelmel JP, Abdullah L, et al. Harmonizing lipidomics: NIST interlaboratory comparison exercise for lipidomics using SRM 1950-metabolites in frozen human plasma. J Lipid Res. (2017) 58:2275-88. doi: 10.1194/jlr.M079012

126. Lipidomics Standards Initiative, C. Lipidomics needs more standardization. Nat Metab. (2019) 1:745-7. doi: 10.1038/s42255-019-0094-z

127. Triebl A, Burla B, Selvalatchmanan J, Oh J, Tan SH, Chan MY, et al. Shared reference materials harmonize lipidomics across MSbased detection platforms and laboratories. J Lipid Res. (2020) 61:10515. doi: 10.1194/jlr.D119000393

128. Gika HG, Macpherson E, Theodoridis GA, Wilson ID. Evaluation of the repeatability of ultra-performance liquid chromatography-TOF-MS for global metabolic profiling of human urine samples. J Chromatogr. (2008) 871:299-305. doi: 10.1016/j.jchromb.2008.05.048

129. Gika HG, Theodoridis GA, Wingate JE, Wilson ID. Within-day reproducibility of an HPLC-MS-based method for metabonomic analysis: application to human urine. J Proteome Res. (2007) 6:3291-303. doi: 10.1021/pr070183p

130. Brunius C, Shi L, Landberg R. Large-scale untargeted LC-MS metabolomics data correction using between-batch feature alignment and clusterbased within-batch signal intensity drift correction. Metabolomics. (2016) 12:173. doi: 10.1007/s11306-016-1124-4

131. Wehrens R, Hageman JA, van Eeuwijk F, Kooke R, Flood PJ, Wijnker E, et al. Improved batch correction in untargeted MS-based metabolomics. Metabolomics. (2016) 12:88. doi: 10.1007/s11306-016-1015-8

132. Shaner RL, Allegood JC, Park H, Wang E, Kelly S, Haynes CA, et al. Quantitative analysis of sphingolipids for lipidomics using triple quadrupole and quadrupole linear ion trap mass spectrometers. J Lipid Res. (2009) 50:1692-707. doi: 10.1194/jlr.D800051-JLR200

133. Parchem K, Sasson S, Ferreri C, Bartoszek A. Qualitative analysis of phospholipids and their oxidised derivatives - used techniques and examples of their applications related to lipidomic research and food analysis. Free Radic Res. (2019) 53:1068-100. doi: 10.1080/10715762.2019.1 657573

134. Byrdwell WC. Atmospheric pressure chemical ionization mass spectrometry for analysis of lipids. Lipids. (2001) 36:32746. doi: 10.1007/s11745-001-0725-5

135. Bielawski J, Pierce JS, Snider J, Rembiesa B, Szulc ZM, Bielawska A, et al. Sphingolipid analysis by high performance liquid chromatography-tandem mass spectrometry (HPLC-MS/MS). Adv Exp Med Biol. (2010) 688:4659. doi: 10.1007/978-1-4419-6741-1_3

136. Bielawski J, Szulc ZM, Hannun YA, Bielawska, A. Simultaneous quantitative analysis of bioactive sphingolipids by high-performance liquid chromatography-tandem mass spectrometry. Methods. (2006) 39:82-91. doi: 10.1016/j.ymeth.2006.05.004

137. Brugger, B. Lipidomics: analysis of the lipid composition of cells and subcellular organelles by electrospray ionization mass spectrometry. Annu Rev Biochem. (2014) 83:7998. doi: 10.1146/annurev-biochem-060713-035324

138. Sullards MC. Analysis of sphingomyelin, glucosylceramide, ceramide, sphingosine, and sphingosine 1-phosphate by tandem mass spectrometry. Methods Enzymol. (2000) 312:32-45. doi: 10.1016/S0076-6879(00)12898-8

139. Weir JM, Wong G, Barlow CK, Greeve MA, Kowalczyk A, Almasy L, et al. Plasma lipid profiling in a large population-based cohort. J Lipid Res. (2013) 54:2898-908. doi: 10.1194/jlr.P035808

140. Stevens VL, Hoover E, Wang Y, Zanetti KA. Pre-analytical factors that affect metabolite stability in human urine, plasma, and serum: a review. Metabolites. (2019) 9:156. doi: 10.3390/metabo9080156

141. Sales S, Graessler J, Ciucci S, Al-Atrib R, Vihervaara T, Schuhmann K, et al. Gender, contraceptives and individual metabolic predisposition shape a healthy plasma lipidome. Sci Rep. (2016) 6:27710. doi: 10.1038/srep27710

142. Gonzalez-Dominguez R, Gonzalez-Dominguez A, Sayago A, FernandezRecamales A. Recommendations and Best practices for standardizing the pre-analytical processing of blood and urine samples in metabolomics. Metabolites. (2020) 10:229. doi: 10.3390/metabo10060229

143. Breier M, Wahl S, Prehn C, Fugmann M, Ferrari U, Weise $\mathrm{M}$, et al. Targeted metabolomics identifies reliable and stable metabolites in human serum and plasma samples. PLOS ONE. (2014) 9:e89728. doi: 10.1371/journal.pone.0089728

144. Wood JT, Williams JS, Pandarinathan L, Courville A, Keplinger MR, Janero DR, et al. Comprehensive profiling of the human circulating endocannabinoid metabolome: clinical sampling and sample storage parameters. Clin Chem Lab Med. (2008) 46:1289-95. doi: 10.1515/CCLM.2008.242

145. Hirayama A, Sugimoto M, Suzuki A, Hatakeyama Y, Enomoto A, Harada S, et al. Effects of processing and storage conditions on charged metabolomic profiles in blood. Electrophoresis. (2015) 36:214855. doi: 10.1002/elps.201400600

146. Frej C, Andersson A, Larsson B, Guo LJ, Norstrom E, Happonen KE, et al. Quantification of sphingosine 1-phosphate by validated LC-MS/MS method revealing strong correlation with apolipoprotein $\mathrm{M}$ in plasma but not in serum due to platelet activation during blood coagulation. Anal Bioanal Chem. (2015) 407:8533-42. doi: 10.1007/s00216-015-9008-4

147. Yu Z, Kastenmuller G, He Y, Belcredi P, Moller G, Prehn C, et al. Differences between human plasma and serum metabolite profiles. PLOS ONE. (2011) 6:e21230. doi: 10.1371/journal.pone.0021230

148. Liu X, Hoene M, Wang X, Yin P, Haring HU, Xu G, et al. Serum or plasma, what is the difference? Investigations to facilitate the sample material selection decision making process for metabolomics studies and beyond. Anal Chim Acta. (2018) 1037:293-300. doi: 10.1016/j.aca.2018.03.009

149. Vogt K, Mahajan-Thakur S, Wolf R, Broderdorf S, Vogel C, Bohm A, et al. Release of platelet-derived sphingosine-1-phosphate involves multidrug resistance protein $4(\mathrm{mrp} 4 / \mathrm{abcc} 4)$ and is inhibited by statins. Thromb Haemost. (2018) 118:132-42. doi: 10.1160/TH17-04-0291

150. Tripodi, A. Laboratory testing for lupus anticoagulants: a review of issues affecting results. Clin Chem. (2007) 53:162935. doi: 10.1373/clinchem.2007.089524

151. Stang LJ, Mitchell LG. Specimen requirements for the haemostasis laboratory. Methods Mol Biol. (2013) 992:4971. doi: 10.1007/978-1-62703-339-8_4

152. Yin P, Peter A, Franken H, Zhao X, Neukamm SS, Rosenbaum L, et al. Preanalytical aspects and sample quality assessment in metabolomics studies of human blood. Clin Chem. (2013) 59:833-45. doi: 10.1373/clinchem.2012.199257

153. Kamlage B, Maldonado SG, Bethan B, Peter E, Schmitz O, Liebenberg V, et al. Quality markers addressing preanalytical variations of blood and plasma processing identified by broad and targeted metabolite profiling. Clin Chem. (2014) 60:399-412. doi: 10.1373/clinchem.2013.211979

154. Ceglarek U, Dittrich J, Helmschrodt C, Wagner K, Nofer JR, Thiery J, et al. Preanalytical standardization of sphingosine-1-phosphate, sphinganine1-phosphate and sphingosine analysis in human plasma by liquid chromatography-tandem mass spectrometry. Clin Chim Acta. (2014) 435:16. doi: 10.1016/j.cca.2014.04.010

155. Schwarz N, Knutti N, Rose M, Neugebauer S, Geiger J, Jahns R, et al. Quality assessment of the preanalytical workflow in liquid biobanking: taurine 
as a serum-specific quality indicator for preanalytical process variations. Biopreserv Biobank. (2019) 17:458-67. doi: 10.1089/bio.2019.0004

156. Haid M, Muschet C, Wahl S, Romisch-Margl W, Prehn C, Moller G, et al. Long-term stability of human plasma metabolites during storage at-80 degrees C. J Proteome Res. (2018) 17:203-11. doi: 10.1021/acs.jproteome.7b00518

157. Shih WJ, Bachorik PS, Haga JA, Myers GL, Stein EA. Estimating the longterm effects of storage at -70 degrees $\mathrm{C}$ on cholesterol, triglyceride, and HDL-cholesterol measurements in stored sera. Clin Chem. (2000) 46:35164. doi: 10.1093/clinchem/46.3.351

158. Schlotterbeck J, Chatterjee M, Gawaz M, Lammerhofer M. Comprehensive MS/MS profiling by UHPLC-ESI-QTOF-MS/MS using SWATH dataindependent acquisition for the study of platelet lipidomes in coronary artery disease. Anal Chim Acta. (2019) 1046:1-15. doi: 10.1016/j.aca.2018.08.060

159. Kailashiya, J. Platelet-derived microparticles analysis: techniques, challenges and recommendations. Anal Biochem. (2018) 546:7885. doi: 10.1016/j.ab.2018.01.030

160. Pienimaeki-Roemer A, Kuhlmann K, Bottcher A, Konovalova T, Black A, Orso E, et al. Lipidomic and proteomic characterization of platelet extracellular vesicle subfractions from senescent platelets. Transfusion. (2015) 55:507-21. doi: 10.1111/trf.12874

161. Pienimaeki-Roemer A, Ruebsaamen K, Boettcher A, Orso E, Scherer M, Liebisch G, et al. Stored platelets alter glycerophospholipid and sphingolipid species, which are differentially transferred to newly released extracellular vesicles. Transfusion. (2013) 53:612-26. doi: 10.1111/j.1537-2995.2012.03775.x

162. Skotland T, Sandvig K, Llorente A. Lipids in exosomes: Current knowledge and the way forward. Prog Lipid Res. (2017) 66:30-41. doi: 10.1016/j.plipres.2017.03.001

163. Boilard E, Duchez AC, Brisson, A. The diversity of platelet microparticles. Curr Opin Hematol. (2015) 22:43744. doi: 10.1097/MOH.0000000000000166

164. Sodar BW, Kittel A, Paloczi K, Vukman KV, Osteikoetxea X, SzaboTaylor $\mathrm{K}$, et al. Low-density lipoprotein mimics blood plasma-derived exosomes and microvesicles during isolation and detection. Sci Rep. (2016) 6:24316. doi: $10.1038 /$ srep24316

165. Li P, Kaslan M, Lee SH, Yao J, Gao Z. Progress in exosome isolation techniques. Theranostics. (2017) 7:789-804. doi: 10.7150/thno.18133

166. Aatonen M, Valkonen S, Boing A, Yuana Y, Nieuwland R, Siljander P, et al. Isolation of platelet-derived extracellular vesicles. Methods Mol Biol. (2017) 1545:177-88. doi: 10.1007/978-1-4939-6728-5_12

167. Stranska R, Gysbrechts L, Wouters J, Vermeersch P, Bloch K, Dierickx D, et al. Comparison of membrane affinity-based method with size-exclusion chromatography for isolation of exosome-like vesicles from human plasma. J Transl Med. (2018) 16:1. doi: 10.1186/s12967-017-1374-6

168. Lane RE, Korbie D, Trau M, Hill MM. Purification protocols for extracellular vesicles. Methods Mol Biol. (2017) 1660:11130. doi: 10.1007/978-1-4939-7253-1_10

169. Woth G, Tokes-Fuzesi M, Magyarlaki T, Kovacs GL, Vermes I, Muhl D, et al. Activated platelet-derived microparticle numbers are elevated in patients with severe fungal (Candida albicans) sepsis. Ann Clin Biochem. (2012) 49:554-60. doi: 10.1258/acb.2012.011215

170. Geeurickx E, Hendrix A. Targets, pitfalls and reference materials for liquid biopsy tests in cancer diagnostics. Mol Aspects Med. (2020) 72:100828. doi: 10.1016/j.mam.2019.10.005

171. Gezsi A, Kovacs A, Visnovitz T, Buzas EI. Systems biology approaches to investigating the roles of extracellular vesicles in human diseases. Exp Mol Med. (2019) 51:1-11. doi: 10.1038/s12276-019-0226-2

172. Kerris EWJ, Hoptay C, Calderon T, Freishtat RJ. Platelets and platelet extracellular vesicles in hemostasis and sepsis. J Invest Med. (2020) 68:81320. doi: 10.1136/jim-2019-001195

173. Blachnio-Zabielska A, Baranowski M, Wojcik B, Gorski J. Reduction of ceramide de novo synthesis in solid tissues changes sphingolipid levels in rat plasma, erythrocytes and platelets. Adv Med Sci. (2016) 61:727. doi: $10.1016 /$ j.advms.2015.09.006

174. Pretorius E, du Plooy JN, Bester J. A Comprehensive review on eryptosis. Cell Physiol Biochem. (2016) 39:1977-2000. doi: 10.1159/000447895

175. Briglia M, Rossi MA, Faggio C. Eryptosis: ally or enemy. Curr Med Chem. (2017) 24:937-42. doi: 10.2174/0929867324666161118142425
176. Lang F, Gulbins E, Lang PA, Zappulla D, Foller M. Ceramide in suicidal death of erythrocytes. Cell Physiol Biochem. (2010) 26:218. doi: $10.1159 / 000315102$

177. Lang E, Bissinger R, Gulbins E, Lang F. Ceramide in the regulation of eryptosis, the suicidal erythrocyte death. Apoptosis. (2015) 20:75867. doi: 10.1007/s10495-015-1094-4

178. Vu TM, Ishizu AN, Foo JC, Toh XR, Zhang F, Whee DM, et al. Mfsd2b is essential for the sphingosine-1-phosphate export in erythrocytes and platelets. Nature. (2017) 550:524-8. doi: 10.1038/nature24053

179. Beyersdorf $\mathrm{N}$, Muller $\mathrm{N}$. Sphingomyelin breakdown in T cells: role in activation, effector functions and immunoregulation. Biol Chem. (2015) 396:749-58. doi: 10.1515/hsz-2014-0282

180. Chiricozzi E, Loberto N, Schiumarini D, Samarani M, Mancini G, Tamanini A, et al. Sphingolipids role in the regulation of inflammatory response: from leukocyte biology to bacterial infection. J Leukoc Biol. (2018) 103:44556. doi: 10.1002/JLB.3MR0717-269R

181. Boyum A. Isolation of mononuclear cells and granulocytes from human blood. Isolation of monuclear cells by one centrifugation, and of granulocytes by combining centrifugation and sedimentation at $1 \mathrm{~g}$. Scand J Clin Lab Invest Suppl. (1968) 97:77-89.

182. Jia Y, Xu H, Li Y, Wei C, Guo R, Wang F, et al. A modified ficoll-paque gradient method for isolating mononuclear cells from the peripheral and umbilical cord blood of humans for biobanks and clinical laboratories. Biopreserv Biobank. (2018) 16:82-91. doi: 10.1089/bio.2017.0082

183. Perper RJ, Zee TW, Mickelson MM. Purification of lymphocytes and platelets by gradient centrifugation. J Lab Clin Med. (1968) 72:842-8.

184. Schramm M, Herz J, Haas A, Kronke M, Utermohlen O. Acid sphingomyelinase is required for efficient phago-lysosomal fusion. Cell Microbiol. (2008) 10:1839-53. doi: 10.1111/j.1462-5822.2008.01169.x

185. Chung HY, Hupe DC, Otto GP, Sprenger M, Bunck AC, Dorer MJ, et al. Acid sphingomyelinase promotes endothelial stress response in systemic inflammation and sepsis. Mol Med. (2016) 22:412-23. doi: 10.2119/molmed.2016.00140

186. Chung HY, Wickel J, Stuhlmuller B, Kinne RW, Claus RA. Acid sphingomyelinase activity is elevated in the serum of rheumatoid arthritis patients, suppressed by anti-TNF-alpha treatment. Clin Exp Rheumatol. (2019) 37 (Suppl. 122):18-9.

187. Corriden R, Hollands A, Olson J, Derieux J, Lopez J, Chang JT, et al. Tamoxifen augments the innate immune function of neutrophils through modulation of intracellular ceramide. Nat Commun. (2015) 6:8369. doi: $10.1038 /$ ncomms 9369

188. Peng H, Li C, Kadow S, Henry BD, Steinmann J, Becker KA, et al. Acid sphingomyelinase inhibition protects mice from lung edema and lethal staphylococcus aureus sepsis. J Mol Med. (2015) 93:67589. doi: 10.1007/s00109-014-1246-y

189. Li C, Wu Y, Riehle A, Orian-Rousseau V, Zhang Y, Gulbins E, et al. Regulation of staphylococcus aureus infection of macrophages by CD44, reactive oxygen species, and acid sphingomyelinase. Antioxid Redox Signal. (2018) 28:91634. doi: 10.1089/ars.2017.6994

190. Bielawski J, Pierce JS, Snider J, Rembiesa B, Szulc ZM, Bielawska A, et al. Comprehensive quantitative analysis of bioactive sphingolipids by highperformance liquid chromatography-tandem mass spectrometry. Methods Mol Biol. (2009) 579:443-67. doi: 10.1007/978-1-60761-322-0_22

191. Gonzalez-Riano C, Dudzik D, Garcia A, Gil-de-la-Fuente A, Gradillas A, Godzien J, et al. Recent developments along the analytical process for metabolomics workflows. Anal Chem. (2020) 92:203-26. doi: 10.1021/acs.analchem. 9b04553

Conflict of Interest: The authors declare that the research was conducted in the absence of any commercial or financial relationships that could be construed as a potential conflict of interest.

Copyright $\odot 2021$ Claus and Graeler. This is an open-access article distributed under the terms of the Creative Commons Attribution License (CC BY). The use, distribution or reproduction in other forums is permitted, provided the original author(s) and the copyright owner(s) are credited and that the original publication in this journal is cited, in accordance with accepted academic practice. No use, distribution or reproduction is permitted which does not comply with these terms. 